\title{
Perturbed Developmental Serotonin Signaling Affects Prefrontal Catecholaminergic Innervation and Cortical Integrity
}

\author{
Lidiane P. Garcia ${ }^{1}$. Josefine S. Witteveen ${ }^{1}$. Anthonieke Middelman ${ }^{2}$. Josephus A. van Hulten ${ }^{1}$. \\ Gerard J. M. Martens ${ }^{1}$ - Judith R. Homberg ${ }^{2}$. Sharon M. Kolk ${ }^{1}$
}

Received: 30 October 2017 / Accepted: 3 May 2018 / Published online: 9 June 2018

(C) The Author(s) 2018

\begin{abstract}
Proper development of the medial prefrontal cortex (mPFC), crucial for correct cognitive functioning, requires projections from, among others, the serotonergic (5-HT) and catecholaminergic systems, but it is unclear how these systems influence each other during development. Here, we describe the parallel development of the 5-HT and catecholaminergic prefrontal projection systems in rat and demonstrate a close engagement of both systems in the proximity of Cajal-Retzius cells. We further show that in the absence of the 5-HT transporter (5-HTT), not only the developing 5-HT but also the catecholaminergic system, including their projections towards the $\mathrm{mPFC}$, are affected. In addition, the layer identity of the $\mathrm{mPFC}$ neurons and reelin-positive interneuron number and integration are altered in the absence of the 5-HTT. Together, our data demonstrate a functional interplay between the developing MPFC 5-HT and catecholaminergic systems, and call for a holistic approach in studying neurotransmitter systems-specific developmental consequences for adult behavior, to eventually allow the design of better treatment strategies for neuropsychiatric disorders.
\end{abstract}

Keywords Neurodevelopment $\cdot$ Prefrontal cortex $(\mathrm{PFC}) \cdot 5$-HT $\cdot \mathrm{TH} \cdot$ Cajal-Retzius

\section{Introduction}

Proper functioning of neural systems and correct targeting of their often long projections to distant targets is crucial for cognitive performance. An important distant target of many neurotransmitter systems is the prefrontal cortex (PFC). The PFC is considered critical for executive and higher cognitive functioning [1-3].

Lidiane P. Garcia and Josefine S. Witteveen contributed equally to this work.

Electronic supplementary material The online version of this article (https://doi.org/10.1007/s12035-018-1105-x) contains supplementary material, which is available to authorized users.

Sharon M. Kolk

S.Kolk@ncmls.ru.nl

1 Donders Institute for Brain, Cognition, and Behaviour, Centre for Neuroscience, Department of Molecular Animal Physiology, Radboud Institute for Molecular Life Sciences (RIMLS), Radboud University Nijmegen, Geert Grooteplein Zuid 28, 6525 GA Nijmegen, The Netherlands

2 Donders Institute for Brain, Cognition, and Behaviour, Centre for Neuroscience, Department of Cognitive Neuroscience, Radboud University Nijmegen Medical Centre, Nijmegen, The Netherlands
Embryonic and early postnatal PFC development is directed by a sequence of intrinsic (e.g., proliferation, migration, and differentiation) and extrinsic (e.g., incoming projections/GABAergic interneurons) events which both can be affected in neurological and psychiatric disorders $[1,4,5]$. During development, the migration of newborn neurons establishes the characteristic insideout layering of the PFC that furthermore receives numerous projections from various neurotransmitter systems, including the dopaminergic (DA), noradrenergic (NA), and serotonergic (5-hydroxytryptamine or 5-HT) systems [6-10]. It is unclear, however, how these systems interact during development and whether they influence each other. Cognitive and emotional disturbances are often attributed to the perturbed projection to the PFC of more than one neurotransmitter system [11-14], including the catecholaminergic and 5-HT systems, in neurological psychiatric disorders [15-22]. The 5-HT system clearly interacts with the catecholaminergic system in adulthood but it remains to be elucidated how they interrelate during PFC development.

The 5-HT system is one of the earliest to emerge and sends out projections (around E10.5 in mice, E12 in rat) to cortical areas during embryonic development [23, 24]. The rostral raphe comprises 5-HT cell clusters in the dorsal raphe (DR, $\mathrm{B} 6$, and $\mathrm{B} 7)$ and the median raphe (MnR, B5, and $\mathrm{B} 8)$ that 
project to the forebrain with predominantly the medial part of the DR projecting to the PFC where they arrive around E16 [25-27]. It has become increasingly clear that 5-HT, but also other neurotransmitters, can act as a neurodevelopmental signal instructing the brain as time proceeds [28-31]. In fact, 5HT is able to modulate neurodevelopmental processes like proliferation, migration, and differentiation [30, 32]. Within cortical areas, presumptive layer 1 Cajal-Retzius (CR) cells receive serotonergic and noradrenergic synaptic input during embryonic development and might therefore control their functioning $[6,33,34]$. Initially, CR cells secrete reelin which has been proven to be important for the specific inside-out patterning of cortical layers [35-37]. Later, CR cells develop into a heterogeneous population of GABAergic interneurons [38-40]. It remains to be determined however how exactly disturbance of the developing 5-HT system influences the intrinsic neurodevelopmental events of the PFC.

The catecholaminergic system sends out projections to the forebrain approximately at the same time as the 5-HT system (E11.5 in mice, E13 in rat) [9, 41-43]. Tyrosine hydroxylaseor TH-positive axons from the rostral part of the ventral tegmental area (VTA) arrive in the PFC around E15, somewhat earlier than the 5-HT system, in two streams within the subplate (SP) and the marginal zone (MZ) where the CR cells reside $[9,44]$. Although it remains speculative to what extent the catecholaminergic projections within the MZ are in synaptic contact with the CR cells, it is known that DA plays a developmental as well as a maturational role in prefrontal areas [45-49]. DAergic projections to the PFC are able to modulate proliferation, migration, and differentiation processes, and any interference during development could contribute to the cortical dysfunction in neuropsychiatric disorders [50].

Until recently, research was focused on understanding the ontogeny and functioning of separate neurotransmitter systems. However, comprehending the development and functioning of the brain in all its facets requires detailed knowledge of how various neural systems interact. In the adult brain, there is a clear interaction between the 5-HT and catecholaminergic projections towards the PFC, especially in the light of their engaged involvement in higher-order cognitive functioning $[12,15,51]$. Anatomically, the two systems considerably overlap in adulthood and seem to receive inputs from one another [52-54]. Less is known, however, about the extent to which the 5-HT and catecholaminergic systems influence each other during neurodevelopment $[51,55]$.

Here, we describe the parallel development of the 5-HT and catecholaminergic systems in the rat between E16 and P6 with special emphasis on their common projection target, the medial PFC (mPFC). We show that in the absence of the 5-HT transporter (5-HTT), not only the 5-HT but also the catecholaminergic system, including TH-positive projections towards the $\mathrm{mPFC}$, are affected. Within the $\mathrm{mPFC}$, the reelincontaining CR cells are in close proximity to 5-HT and $\mathrm{TH}-$ positive fibers, and in the absence of the 5-HTT, they differ in number. We furthermore demonstrate that the identity of especially deep-layer neurons is altered in the $5-\mathrm{HTT}^{-/-}$rats. Altogether, these data suggest that there is a functional interplay between the 5-HT and catecholaminergic systems during development leading to a distortion of the cytoarchitecture of the PFC. Thus, the possible interplay of multiple neural neurotransmitter systems during development has to be taken into account when studying the etiology of neuropsychiatric disorders.

\section{Materials and Methods}

\section{Animals}

The control neuroanatomical descriptions were performed on wildtype rats of the Wistar background purchased from a commercial breeder (Janvier, Labs, RjHan:WI; Hannover, Germany). The generation of the Slc6a $4^{1 \mathrm{Hubr}}$ wildtype (5$\left.\mathrm{HTT}^{+/+}\right)$and mutant rats $\left(5-\mathrm{HTT}^{-/}\right)$has been described previously [56]. They were bred onto a Wistar genetic background. The day of the plug was considered to be embryonic day (E) 0 and the day of birth to be postnatal day (P)0. All experiments were performed in compliance with the standard ethics guidelines of the European Community and in accordance with the recommendations of the local animal welfare committee (DEC) of the Radboud University. The protocol was approved by the DEC. Male and female embryos and pups were used indiscriminately in all experiments and sacrificed by decapitation.

\section{Section Preparation and Immunohistochemistry}

Brains were rapidly dissected from E16.5, E18.5, and E20.5 embryos, P6 pups, and P25 adolescents, and fixed by immersion for $0.5-1.5 \mathrm{~h}$ in $4 \%$ paraformaldehyde (PFA) in phosphate-buffered saline (PBS), pH 7.4. After fixation, brains were washed in PBS, cryoprotected in $30 \%$ sucrose overnight, frozen in M-1 embedding matrix (Shandon, Thermo Fisher Scientific Inc., Waltham, MA, USA) on dry ice in a plastic cup, and stored at $-80^{\circ} \mathrm{C}$. Cryostat coronal or sagittal sections were cut at $16 \mu \mathrm{m}$, mounted as series of 6-8 on Superfrost Plus slides (Thermo Fisher Scientific), air-dried, and stored desiccated at $-20^{\circ} \mathrm{C}$. Cryosections were stained immunohistochemically and imaged as described previously $[10,57]$ with the following exceptions; incubation of P6 and P25 sections with primary antibodies was done for either $3 \mathrm{~h}$ at room temperature (RT) or overnight $(\mathrm{ON})$ at $4{ }^{\circ} \mathrm{C}$. Immunofluorescence was visualized using either an Invitrogen/Thermo Fisher Scientific EVOSTM FL Auto Imaging System with a high-sensitivity CMOS camera or EVOS FL Auto Software or using a Leica DMRA 
fluorescence microscope coupled with a DFC340FX digital camera and LASAF software. The primary antibodies, dilutions used, and antibody suppliers can be found in Table 1.The nomenclature to describe neurons and axons within different brain areas is as described previously by Schambra et al. [58] and Jacobowitz and Abott [59] and extended as outlined in [9, 10] and in Supplemental Figure 1.

\section{Data Analysis}

All data analyses were performed in a blinded fashion without knowledge of the animal's genotype. For assessing 5-HT- or TH-positive axon length and number of layer marker-positive neurons within the various subareas of the medial PFC (mPFC) of $5-H T T^{+/+}$and of $5-H T T^{-1-}$ rats, three to five P6 pups were analyzed and two to four well-spaced $(120 \mu \mathrm{m})$ sections at the same neuroanatomical level were imaged. A 0.1-mm-wide rectangle spanning the prefrontal wall was placed over the center of the subarea (either infralimbic, IL; prelimbic, PL; or cingulate cortex, $\mathrm{Cg}$ ) of the $\mathrm{mPFC}$. The overall cortical length of a subarea was divided into ten equal bins [bin 1 within the deep cortical layers and bin 10 within the presumptive layer I] within this rectangle, and 5-HT- or TH-positive axon length or number of layer marker-positive neurons were measured within each bin using ImageJ software including the NeuronJ plugin (NIH, Bethesda, USA). Data were normalized to a total length per bin, or to a percentage of the total number of cells and averaged for each pup. To better visualize and compare 5-HT and/or catecholaminergic innervation of wildtype and mutant $\mathrm{mPFC}$, reconstructions of the individual fibers from two to three consecutive sections were obtained bilaterally using the NeuronJ plugin. Data were statistically analyzed by one-way ANOVA $(\alpha=5 \%)$ using Graphpad Prism 6/Excel data analysis toolkit and expressed as means $\pm \mathrm{SEM}$.

Surface area of $\mathrm{TH}^{+}$(tyrosine hydroxylase, rate-limiting enzyme responsible for DA synthesis) area within the ventral midbrain was measured by dividing the area along the midline. The surface area was then measured in $\mu \mathrm{m}^{2}$ with Image $\mathrm{J}$ and averaged between left and right of two to three wellspaced sections. For each $n$, the same neuroanatomical level

Table 1 The primary antibodies, dilutions used, and antibody suppliers

\begin{tabular}{lll}
\hline Antibody & Dilution & Company \\
\hline Rabbit anti-5-hydroxytryptamine (5-HT) & $1: 1000$ & Sigma-Aldrich \\
Mouse anti-Satb2 & $1: 500$ & Abcam \\
Mouse anti-reelin & $1: 500$ & Chemicon \\
Mouse anti-Cux1 & $1: 300$ & Abcam \\
Rabbit anti-tyrosine hydroxylase (TH) & $1: 1000$ & Millipore \\
Chicken anti-tyrosine hydroxylase (TH) & $1: 500$ & Abcam \\
Rabbit anti-Tbr1 & $1: 500$ & Abcam \\
\hline
\end{tabular}

was chosen in terms of rostral-to-caudal extent. The measurements of $5-\mathrm{HT}^{+}$surface area of the B7 and B8 nuclei in the hindbrain was performed in a similar fashion with the exception that the entire nucleus was measured and not divided along the midline. $5-\mathrm{HT}^{+}$cell numbers of the B7 and B8 nuclei were counted in Adobe Photoshop in the same area used to measure the surface area in two to four well-spaced sections. Again, for each $n$, the same neuroanatomical level was chosen in terms of rostral-to-caudal extent. Data were statistically analyzed by one-way ANOVA $(\alpha=5 \%)$ using Graphpad Prism 6/Excel data analysis toolkit and expressed as means \pm SEM.

\section{Results}

\section{Developing 5-HT and Catecholaminergic Systems Targeting the MPFC}

In rats, 5-HT neurons start extending axons by E12 and $\mathrm{TH}^{+}$ axons by E13 [9, 23]. Both neurotransmitter systems send out ascending axonal projections to distant forebrain targets including the mPFC $[9,23,43]$. The ontogeny of both systems has been described in detail for each system individually, however little is known of the concurrent development of both systems.

In order to examine the relationship between the developing 5-HT and catecholaminergic system, we immunostained cryosections of developing rat brains (E16, E18, E20, and P6) for TH and 5-HT. Sagittal sections suggest a close interrelationship of especially ascending $\mathrm{TH}^{+}$and $5-\mathrm{HT}^{+}$axons (Fig. 1a-d). When we took a closer look at the origin of both ascending neural systems, the DA midbrain and the 5-HT DR and $\mathrm{MnR}$ at the coronal level, we were able to observe a close contiguity between the $\mathrm{TH}^{+}$and $5-\mathrm{HT}^{+}$axons (Fig. 1e-t). Within the developing DR and MnR, besides the 5-HT neuron clusters, a combination of both $\mathrm{TH}^{+}$axons as well as $\mathrm{TH}^{+}$cell bodies could be observed (Fig. 1e-h). At E16, we observed overlapping positioning of the majority of the TH- and 5-HTpositive neurons (Fig. 1e). At E18, most of the $\mathrm{TH}^{+}$neurons and fibers could be observed dorsally within or near the B7 of the DR (Fig. 1e-h). Within the developing DA midbrain at E16, 5-HT axonal projections were closely intermingled with the developing and still migrating $\mathrm{TH}^{+}$neurons in both the substantia nigra (SN) and the VTA. The latter seemed to be more innervated by 5-HT projections throughout the course of development (Fig. 1i-1).

$\mathrm{TH}^{+}$and 5-HT axons travel together towards forebrain targets and they run in parallel within the median forebrain bundle (MFB). We observed that $\mathrm{TH}^{+}$axons bundle in larger fascicles and reside more dorsal within the extent of the MFB when compared to the 5-HT axons (Fig. 1m-p). The 5-HT axons are located more ventral within the MFB and 


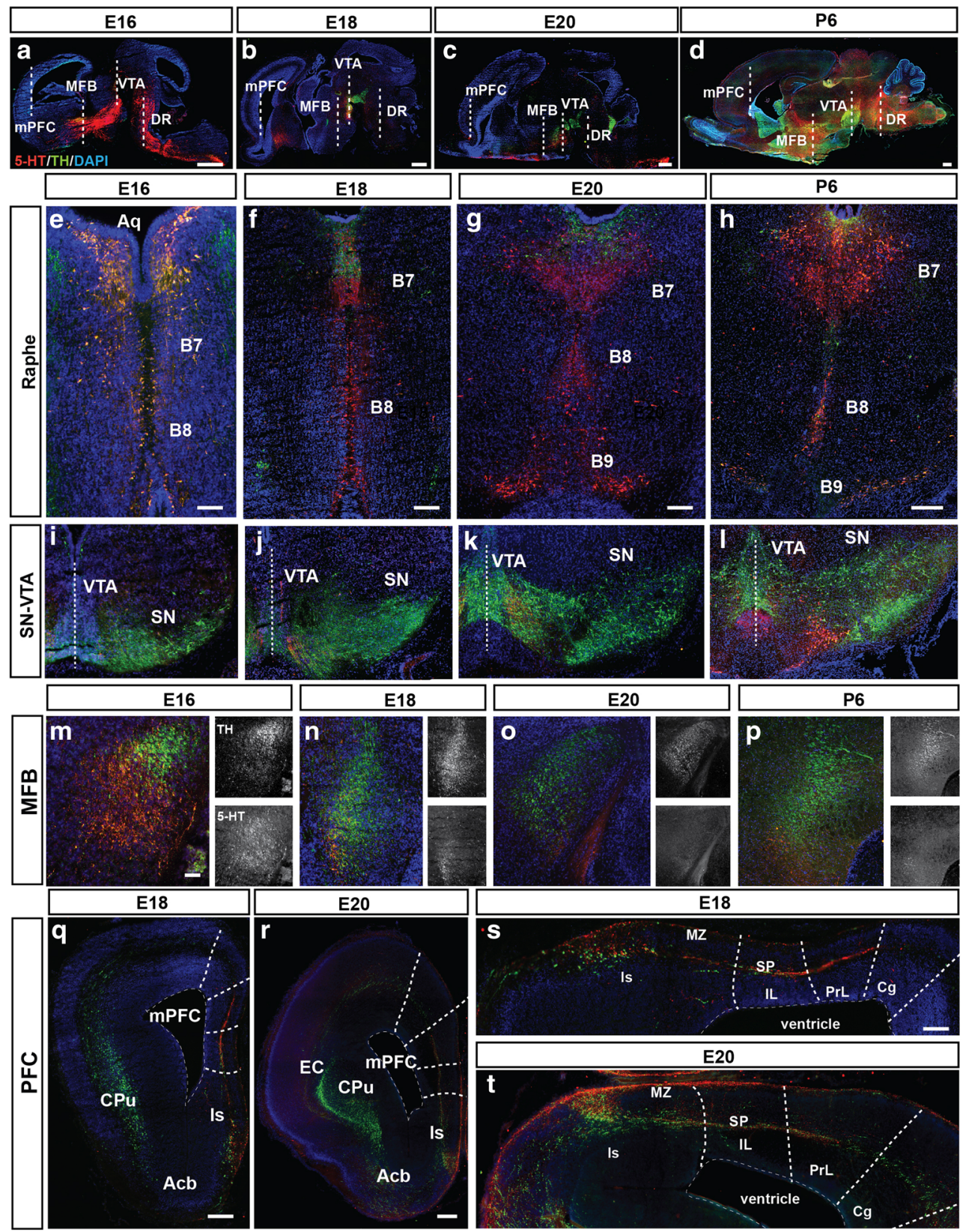

Fig. 1 Developing 5-HT and catecholaminergic systems target the mPFC. Sagittal cryosections of E16 (a), E18 (b), E20 (c), and P6 (d) rat brains immunostained for 5-HT (red) and TH (green) and stained with DAPI (blue) to visualize cell nuclei showing the 5-HT and the catecholaminergic developing systems. Dotted lines indicate the coronal section levels. Enlargements of coronal cryosections of E16 (e), E18 (f), E20 (g), and P6 (h) rat brains immunostained for 5-HT (red) and TH (green) and stained with DAPI (blue) showing the DR with the B7, B8, and/or B9 5-HT-positive cell clusters closely intermingled with THpositive neurons and fibers. Enlargements of coronal cryosections of E16 (i), E18 (j), E20 (k), and P6 (I) rat brains immunostained for 5-HT (red) and TH (green) and stained with DAPI (blue) showing the rostral ventral tegmental area (rVTA) and the substantia nigra (SN) with the THpositive cell clusters/fibers closely intermingled with 5-HT-positive neurons and fibers. Dotted lines indicate the midline. Enlargements of

seemed to get more varicose as development proceeds (Fig. $1 \mathrm{~m}-\mathrm{p}$ ). However, a large proportion of the $\mathrm{TH}^{+}$and 5-

coronal cryosections of E16 (m), E18 (n), E20 (o), and P6 (p) rat brain immunostained for 5-HT (red) and TH (green) and stained with DAPI (blue) showing the medial forebrain bundle (MFB) with TH residing mainly in dorsal fascicles while 5-HT is present mostly within more caudal ones. Coronal (half shown) cryosections of E18 (q) and E20 (r) rat brains immunostained for 5-HT (red) and TH (green) and stained with DAPI (blue) showing the forebrain targets of both systems including the caudate putamen $(\mathrm{CPu})$, the lateral septum (ls), the nucleus accumbens (Acb), and the medial prefrontal cortex (mPFC). Enlargements of the mPFC region of E18 (s) and E20 (t) rat brains showing a TH/5-HTpositive stream above the subplate (SP) and one in the marginal zone (MZ) in all three prefrontal subdomains (infralimbic, IL; prelimbic, PL; and cingulate, $\mathrm{Cg}$ ). 1s, lateral septum. Bar in a-d, $500 \mu \mathrm{m} ; \mathbf{e}, 200 \mu \mathrm{m} ; \mathbf{f}$, $300 \mu \mathrm{m} ; \mathbf{g}, 250 \mu \mathrm{m} ; \mathbf{h}, 200 \mu \mathrm{m} ; \mathbf{i}-\mathbf{l}, 300 \mu \mathrm{m} ; \mathbf{m}-\mathbf{p}, 200 \mu \mathrm{m} ; \mathbf{q}$ and $\mathbf{r}$, $300 \mu \mathrm{m} ; \mathbf{s}$ and $\mathbf{t}, 250 \mu \mathrm{m}$

HT axons coincide, suggesting a close contiguity within the MFB during development (Fig. $1 \mathrm{~m}-\mathrm{p}$ ). 
Eventually, both neural systems reached numerous forebrain targets including the mPFC (Fig. 1q-t). Especially within the region of the lateral septum (ls), the catecholaminergic system concurred with the 5-HT system although there was only partial overlap. Within the mPFC, there are two main fascicle paths of $\mathrm{TH}^{+}$and 5-HT axon bundles. At E18, the first path was observed as a robust bundle of fascicles and individual 5-HT-positive fibers were detected above the subplate (SP) of all three $\mathrm{mPFC}$ subdomains (infralimbic, IL; prelimbic, PL; and Cingulate, $\mathrm{Cg}$ ), although the fibers were less prominent within SP of the $\mathrm{Cg}$ (Fig. 1q-t). TH-positive fibers could also be observed at E18 but were less conspicuous and fasciculated (Fig. 1q-t). The other path of concurring $\mathrm{TH}^{+}$and $5-\mathrm{HT}^{+}$ fibers was found within the marginal zone (MZ) or the presumptive layer 1 where again the presence of 5-HT fibers exceeded that of the $\mathrm{TH}^{+}$ones (Fig. 1q-t). At E20, the innervation within the mPFC subdomains had increased in both paths and both systems innervated the cortical plate (CP) (Fig. 1s, t).

In summary, there is a close intercalation and proximity of the catecholaminergic system and 5-HT system during development. They both innervate the mPFC in a similar pattern and time frame. Although the catecholaminergic system arrives earlier, the 5-HT system remains more prominent throughout development.

\section{Close Proximity of DA and 5-HT Projections Within the Developing MPFC}

There is a vast amount of information on the innervation of the mPFC by each of the catecholaminergic and 5-HT systems. However, less is known about the coinciding innervation of the mPFC during development.

To address the coinciding localization and possible interaction of the catecholaminergic and the 5-HT system within the developing $\mathrm{mPFC}$, we focused on the immunoreactive $\mathrm{TH}$ and 5-HT fibers within the different aspects of the mPFC subdomains. To show the proximity and intercalation of both neural systems, camera lucida drawings were obtained. At E16, no $\mathrm{TH}^{+}$or $5-\mathrm{HT}^{+}$fibers could be observed within all cortical aspects of the individual subdomains (data not shown). At E18, the two above-mentioned paths could be observed especially in the IL and PL (shown) with $\mathrm{TH}^{+}$and $5-\mathrm{HT}^{+}$varicose fibers running above the $\mathrm{SP}$ and within presumptive layer 1 (Fig. 2b, e, and h). Hardly, any innervation of the $\mathrm{CP}$ was present at this time point. At E20, both streams were still prominent with 5 - $\mathrm{HT}^{+}$exceeding $\mathrm{TH}^{+}$fibers in the presumptive layer 1 and to a lesser extent above the SP (Fig. 2c, f, i, and k). Substantial innervation of the CP of mostly $5-\mathrm{HT}^{+}$fibers could also be observed. At P6, extensive innervation by both neurotransmitter systems of all cortical aspects could be observed (Fig. 2d, g, j, and k). Yet, there was a clear 5-HT- and TH-positive band within layer I, which is most likely in close proximity of CR cells (Fig. $2 \mathrm{~b}-\mathrm{j}$ ). $\mathrm{TH}^{+}$ and $5-\mathrm{HT}^{+}$axons seemed to run in close proximity especially early within development but, as was also clear from the camera lucida drawings, they appear to have their own distinct target cells across layers.

Thus, within the developing $\mathrm{MPFC}$, both the catecholaminergic and the 5-HT systems are present and innervate cortical areas via the SP and MZ. Later, a large variety of neurons within the mPFC cortical layers get innervated by both the catecholaminergic as well as the 5-HT system.

\section{The Developing Catecholaminergic System is Affected in the Absence of the 5-HTT}

It is well accepted that 5-HT has an important neurodevelopmental role [30, 60-62]. In previous work, we demonstrated that in the absence of 5-HTT, the amount of 5HT-positive fibers increased dramatically within certain cortical layers of the IL and PL and to a lesser extent of the $\mathrm{Cg}$ ([10] and Fig. 3, Supplemental Figure 1). This raises the question of how elevated levels of extracellular 5-HT during development might influence other neural systems.

To address whether the catecholaminergic system would be affected, we studied P6 brains of the 5-HTT mutant rat model. First, we tried to recapitulate our previous results: the 5-HT innervation of the subdomains of the mPFC was higher in 5$\mathrm{HTT}^{-/-}$animals $(n=5)$ compared to wildtype $(n=5)$. Indeed, we again observed a significant increase of total 5-HT innervation in both the IL $(p=0.000016)$ and PL $(p=0.000059)$ and to a lesser extent in the $\mathrm{Cg}(p=0.11049$; Fig. 3c, f, i). Strikingly, we discovered that the catecholaminergic innervation of the mPFC subdomains is also affected in 5 -HTT ${ }^{-1}$ animals. Within the IL and PL, we found a significant increase of $\mathrm{TH}^{+}$innervation in especially the deeper layers and in bins 10 and 8 (more superficial layers) for the IL and PL of 5$\mathrm{HTT}^{-/-}$animals, respectively (Fig. 3a, b, d, and e). Interestingly, the $\mathrm{TH}^{+}$innervation of the $\mathrm{Cg}$ tended to be higher in the deeper cortical layers whereas it was significantly lower in the more superficial layers, mimicking the results we obtained before for the 5-HT innervation [10] (Fig. 3g-h).

As the $\mathrm{TH}^{+}$and 5-HT innervation of the mPFC was affected in $5-\mathrm{HTT}^{-/}$animals, the question remained whether also the source of the $\mathrm{TH}^{+}$(rostral VTA or rVTA) and 5- $\mathrm{HT}^{+}$(DR and $\mathrm{MnR}$ ) prefrontal fibers were affected by changes in 5-HT levels during development. To this end, we measured the surface area of the DA midbrain including the rVTA and the SN of both $5-\mathrm{HTT}^{-/-}$P6 animals $(n=3)$ and their control counterparts $(n=3)$. The total amount of surface area comprising $\mathrm{TH}^{+}$neurons was significantly lower in $5-\mathrm{HTT}^{-/}$animals as compared to controls ( $p=0.013$; Fig. $4 \mathrm{~g}$ ). In addition, there seemed to be more axons leaving the VTA area and THpositive neurons looked more sparse and disorganized, especially within the SN (Fig. 4d, e). We furthermore measured the 


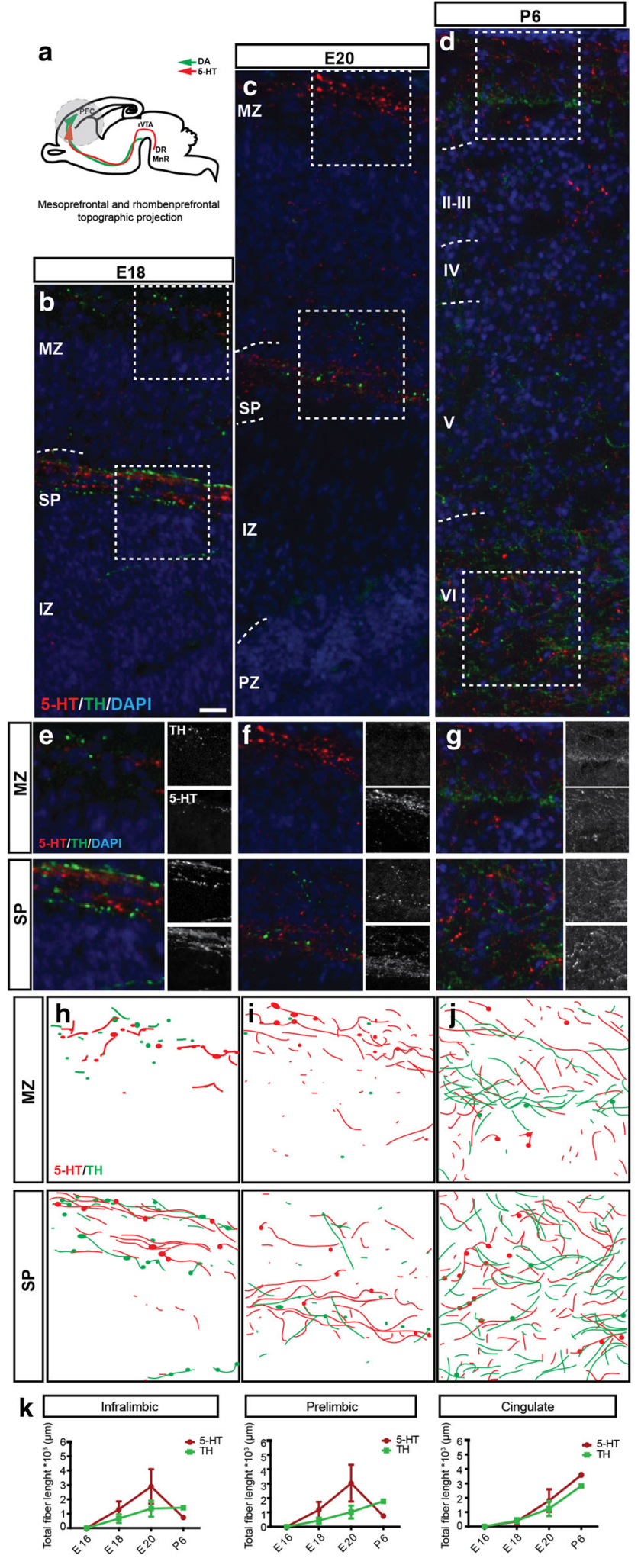

total surface area of the raphe B7 and the B8 cluster in P6 5$\mathrm{HTT}^{-/-}$animals and wildtypes, counted the 5-HT-positive cells in both clusters, and calculated the cell density. The total surface area comprising 5-HT neurons was significantly larger
Fig. 2 Catecholaminergic and 5-HT interaction within the developing mPFC. a Schematic representation of a sagittal view of a developing embryonic rodent brain showing the catecholaminergic mesoprefrontal topographic projection (green arrow) and the 5-HTergic rhomben prefrontal topographic projection (red arrow) highlighting the forebrain target; the mPFC (within the gray circle). Enlargement of coronal cryosections of E18 (b), E20 (c), and P6 (d) rat brains immunostained for 5-HT (red) and TH (green) and stained with DAPI (blue) showing a cortical swatch of the mPFC IL subarea. Enlargements of the boxed areas in B-D showing TH- and 5-HT-positive fibers within the marginal zone (MZ, upper box) and subplate (SP, lower box) region of the E18 (e), E20 (f), and P6 (g) mPFC flanked by the gray-valued separated channels (TH upper and 5-HT lower box). $\mathbf{h}-\mathbf{j}$ Camera lucida drawings of the boxed areas in $\mathbf{b}-\mathbf{d}$ showing the proximity of the TH- (green) with the 5-HTpositive (red) fibers. $\mathbf{k}$ Quantification of the total length of TH (green) and 5-HT-positive (red) fibers within the three subareas (IL, PL, and Cg) of the $\mathrm{mPFC}$. IZ intermediate zone, PZ proliferative zone. Bar in a, $100 \mu \mathrm{m}$; b, $80 \mu \mathrm{m} ; \mathbf{c}, 70 \mu \mathrm{m}$

in both the B7 and the B8 cell cluster in $5-\mathrm{HTT}^{-/-}$animals compared to controls ( $p=0.01$ and $p=0.006$, respectively) Fig. $4 \mathrm{n}, \mathrm{q})$. This was reflected by an increase in length of the B7 cluster and an increase in width of the B8 cluster $(p=0.031)$ and $(p=0.037)$ respectively; Fig. 4o, r). Additionally, the total amount of 5-HT-positive cells within each cluster was significantly lower, resulting in a lower cell density for both cell clusters $(p=0.002$ and $p=0.0002$, respectively; Fig. 4m, p).

Together, we can conclude that when 5-HTT is absent during development, the mesoprefrontal catecholaminergic system and rhomben prefrontal 5-HT system are affected.

\section{Reelin in Relation to 5-HT and Catecholaminergic Signaling}

The 5-HT fibers within the MZ have been shown to contact $\mathrm{CR}$ cells, and thereby control reelin release [6]. By combining immunostaining for 5-HT and for TH, we observed that there are numerous $\mathrm{TH}^{+}$and $5-\mathrm{HT}^{+}$projections running through the $\mathrm{MZ}$ where the CR reside. The question remains, however, to what extent the absence of 5-HTT interferes with reelin release, either directly or indirectly, through altered 5-HT or other projections.

To visualize the proximity of $\mathrm{TH}^{+}$and $5-\mathrm{HT}^{+}$fibers with CR cells, we immunostained cryosections of E18 and E20 with either 5-HT or TH in combination with reelin. Throughout cortical regions, including all subdomains of the mPFC, 5-HT- and TH-positive fibers running through the MZ are in close proximity with CR cells (Fig. 5a-h). Confocal images showed that some varicosities were indeed contacting the CR cells (Fig. 5j and Supplemental Figure 2). Triplelabeling the cryosections with $\mathrm{TH}, 5-\mathrm{HT}$, and reelin revealed that the 5-HT and TH fibers both contact the CR cells, albeit at different sites (Fig. 5i), suggesting that besides the known 5$\mathrm{HT}$, also the TH fibers are in the vicinity to be able to influence $\mathrm{CR}$ cell output and possible reelin release. 

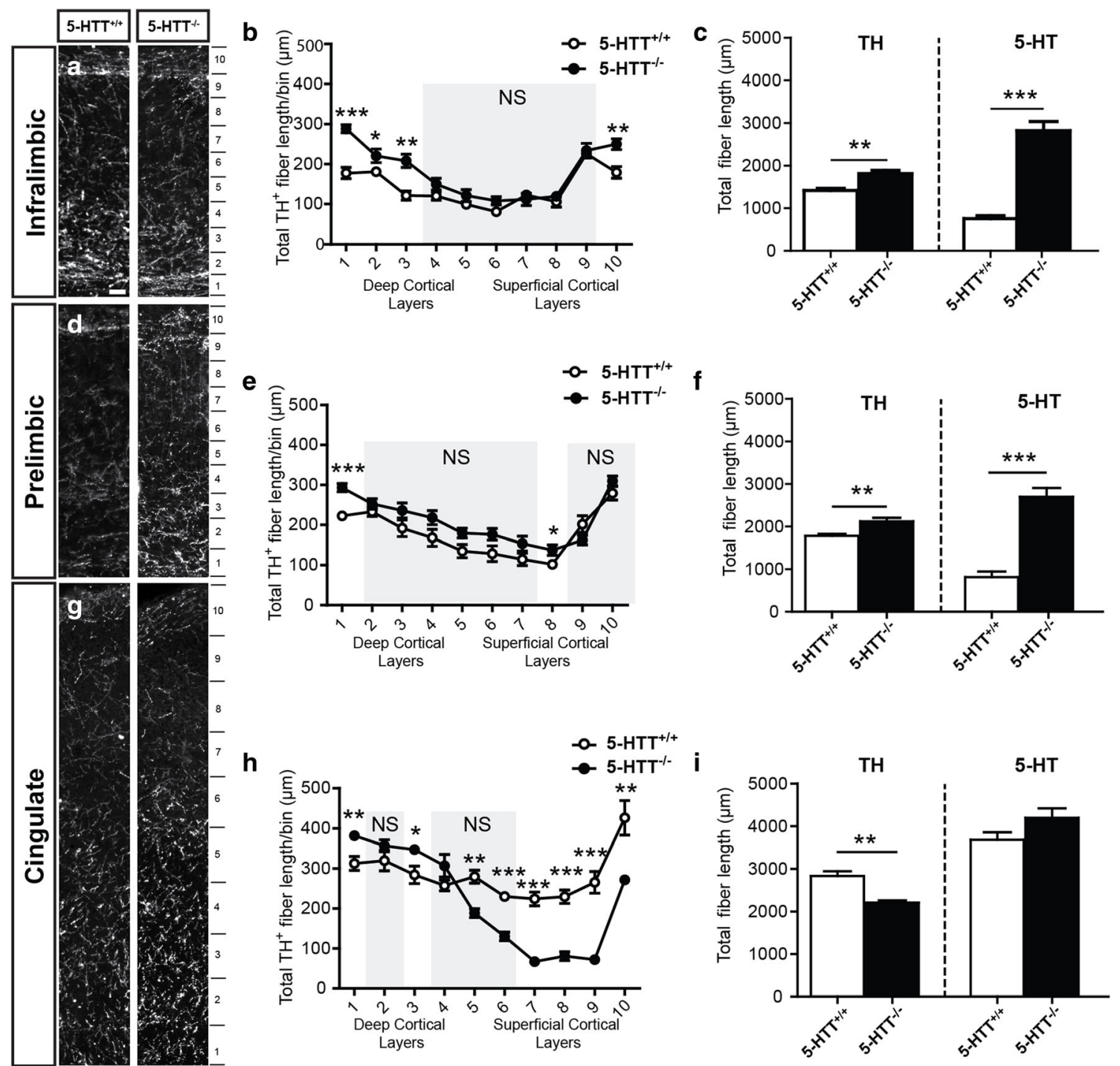

Fig. 3 Catecholaminergic innervation of the mPFC affected in 5-HTTdeficient rat model. Enlargements of cryosections of P6 5- $\mathrm{HTT}^{+/+}$and 5$\mathrm{HTT}^{-/}$rat brains showing prefrontal swatches of the IL (a), PL (d), and the $\mathrm{Cg}(\mathrm{g})$ immunostained for $\mathrm{TH}$ (white). Quantification of the $\mathrm{TH}^{+}$fiber length (in $\mu \mathrm{m}$ ) within the bins indicated in $\mathbf{a}, \mathbf{d}$, and $\mathbf{g}$ in the IL (b), PL (e), and $\mathrm{Cg}(\mathbf{h})$ of $5-\mathrm{HTT}^{-/-}$compared to $5-\mathrm{HTT}^{+/+}$pups confirming the qualitative observations. The gray boxes represent the non-significant (NS) bins. Graphs in b, e, and $\mathbf{h}$ show average total length of TH-

\section{Prefrontal Cytoarchitecture is Affected in the Absence of the 5-HTT}

The fact throughout development, 5-HT and TH fibers reside in close proximity with CR cells and that they are affected in the absence of 5-HTT, made us speculate whether these innervation alterations could have impacted cortical build-up.

To address the question to what extent layer-specific markers were affected, we immunostained mutant and wildtype P6 cryosections for a deep-layer marker, Tbr1 (Fig. 6a-c) and an upper-layer marker, Cux1 (Fig. 6d-f). Indeed, both markers were severely affected in their expression pattern (Fig. 6). The positive fibers per bin \pm SEM. One-way ANOVA, ${ }^{*} p<0.05,{ }^{* *} p<0.01$, ${ }_{* * * *}^{*} p<0.001$. Quantification of the total TH-positive (left) as compared to the total 5-HT-positive fiber length (in $\mu \mathrm{m}$ ) over the complete length of the prefrontal swatch in the IL (c), PL (f), and $\mathrm{Cg}$ (i) of 5-HTT ${ }^{-/}$ compared to $5-\mathrm{HTT}^{+/+}$pups. Graphs in $\mathbf{c}, \mathbf{f}$, and $\mathbf{i}$ show average total length of TH- and 5-HT-positive fibers \pm SEM. One-way ANOVA, ${ }^{* *} p$ $<0.01,{ }^{* * * *} p<0.001$. Bar in all, $50 \mu \mathrm{m}$

percentage of cells affected was significant in all ten bins, but was most striking for the bins in deeper layers, specifically for Tbr1 (Fig. 6a-c). The total number of Cux1- and Tbr1-positive cells was significantly affected as well (Supplemental Figure 3). This is in coherence with our previous findings demonstrating that Satb2, a layer 2-5 marker was severely affected [10]. The total number of cells (DAPI-positive) was not significantly different in IL $(p=0.2)$, PL $(p=0.9)$, and $\mathrm{Cg}(\mathrm{p}=0.9)$; (Supplemental Figure 3), suggesting that the altered layer marker expression is due to an altered identity.

To investigate marker expression at a later developmental age, we immunostained mutant and wildtype P25 cryosections 


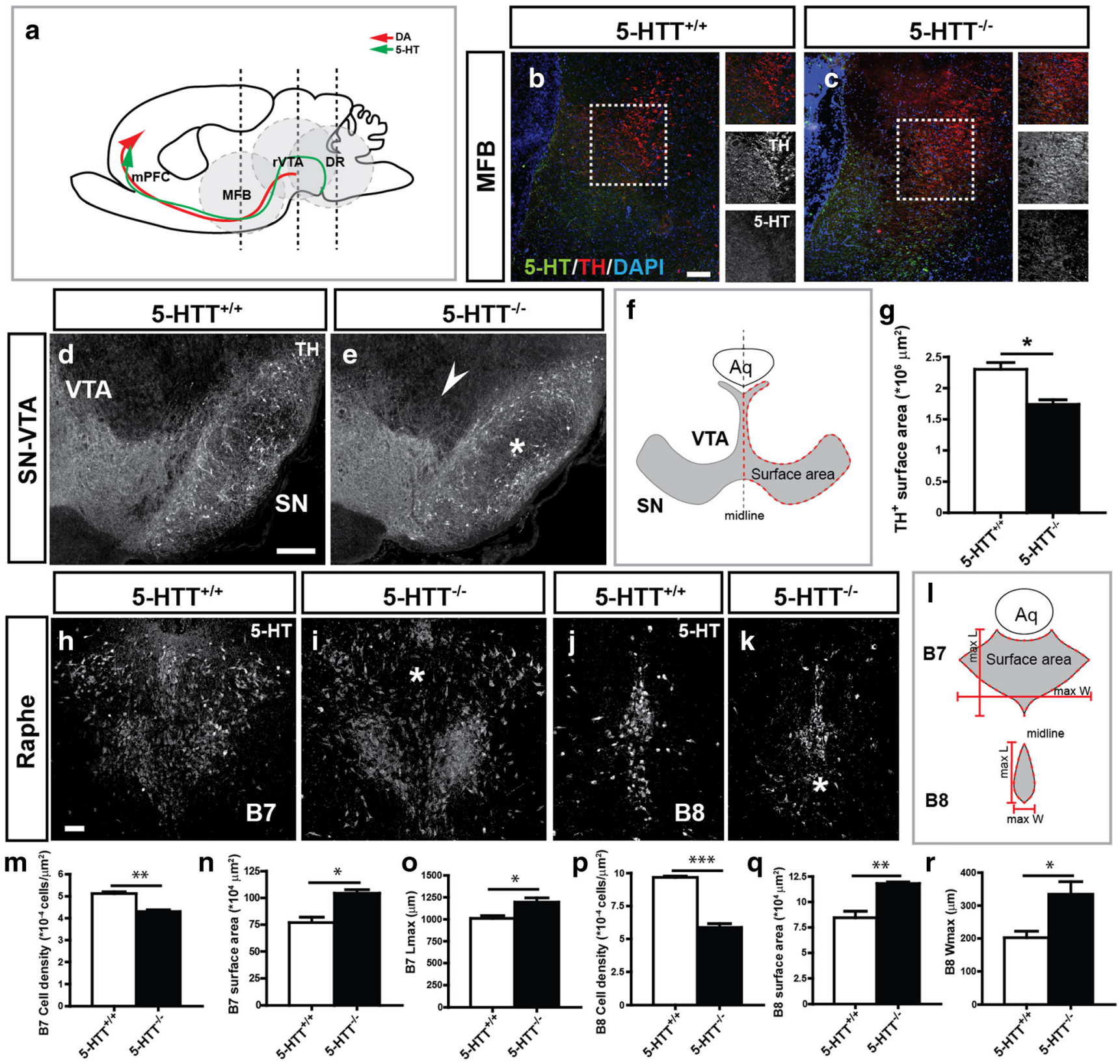

Fig. 4 Catecholaminergic system is affected when 5-HT levels are perturbed during development. a Schematic representation of a sagittal view of a developing postnatal rodent brain showing the catecholaminergic mesoprefrontal topographic projection (red arrow) and the 5-HTergic rhomben prefrontal topographic projection (green arrow) towards the mPFC highlighting the DA origin rVTA, the 5-HT origin DR, and the MFB (within the gray circles). Enlargements of coronal cryosections of P6 rat brain immunostained for 5-HT (red) and $\mathrm{TH}$ (green) and stained with DAPI (blue) showing the MFB of 5-HTT ${ }^{-1}$ (c) compared to 5-HTT ${ }^{+/+}$animals (b) showing a higher level of defasciculation of $\mathrm{TH}^{+}$fibers and a lower level of 5-HT fibers in the 5$\mathrm{HTT}^{-/-}$pups. Boxed area shows the individual fascicles of the catecholaminergic (middle box) and 5-HT (lower box) system. Enlargements of coronal cryosections of P6 rat brain immunostained for $\mathrm{TH}$ (white) showing the rVTA of $5-\mathrm{HTT}^{-/-}$(e) compared to $5-\mathrm{HTT}^{+/+}$(d) animals showing more catecholaminergic fibers exiting the VTA area (arrowhead) and fewer and less organized $\mathrm{TH}^{+}$neurons in the $\mathrm{SN}$ (asterisk) of $5-\mathrm{HTT}^{-/}$pups. f Schematic representation of a coronal view of a developing DA midbrain including the VTA and SN showing the measured surface area (surrounded by red dotted lines). Aq aqueduct. (g) Graph showing the surface area occupied by $\mathrm{TH}^{+}$fibers/neurons \pm SEM which is significantly smaller for $5-\mathrm{HTT}^{-/}$pups. One-way ANOVA, ${ }^{*} p<0.05$. Enlargements of coronal cryosections of P6 rat brain immunostained for 5-HT (white) showing the DR B7 (h, i) and $\mathrm{B} 8(\mathbf{j}, \mathbf{k})$ cell cluster of $5-\mathrm{HTT}^{-/-}(\mathbf{i}, \mathbf{k})$ compared to $5-\mathrm{HTT}^{+/+}(\mathbf{h}, \mathbf{j})$ animals showing irregularities in both cell clusters (asterisks) of 5$\mathrm{HTT}^{-/-}$pups. I Schematic representation of a coronal view of the developing 5-HT raphe area including the B7 and B8 cell clusters showing the measured surface area (surrounded by red dotted lines) and the maximal width $(\max W)$ and the maximal lengths ( $\max L)$ of both clusters (red lines). Aq aqueduct. Quantification of the number of the 5HT-positive neurons in the B7 (m) and B8 (p) cluster, the measured surface area of the B7 (n) and the B8 (q) area, the maximal length of the B7 cluster (o), and the maximal width of the B8 cluster (r). Bar in $\mathbf{b}$ and c, $200 \mu \mathrm{m} ; \mathbf{d}$ and $\mathbf{e}, 300 \mu \mathrm{m} ; \mathbf{h}-\mathbf{k}, 100 \mu \mathrm{m}$ 


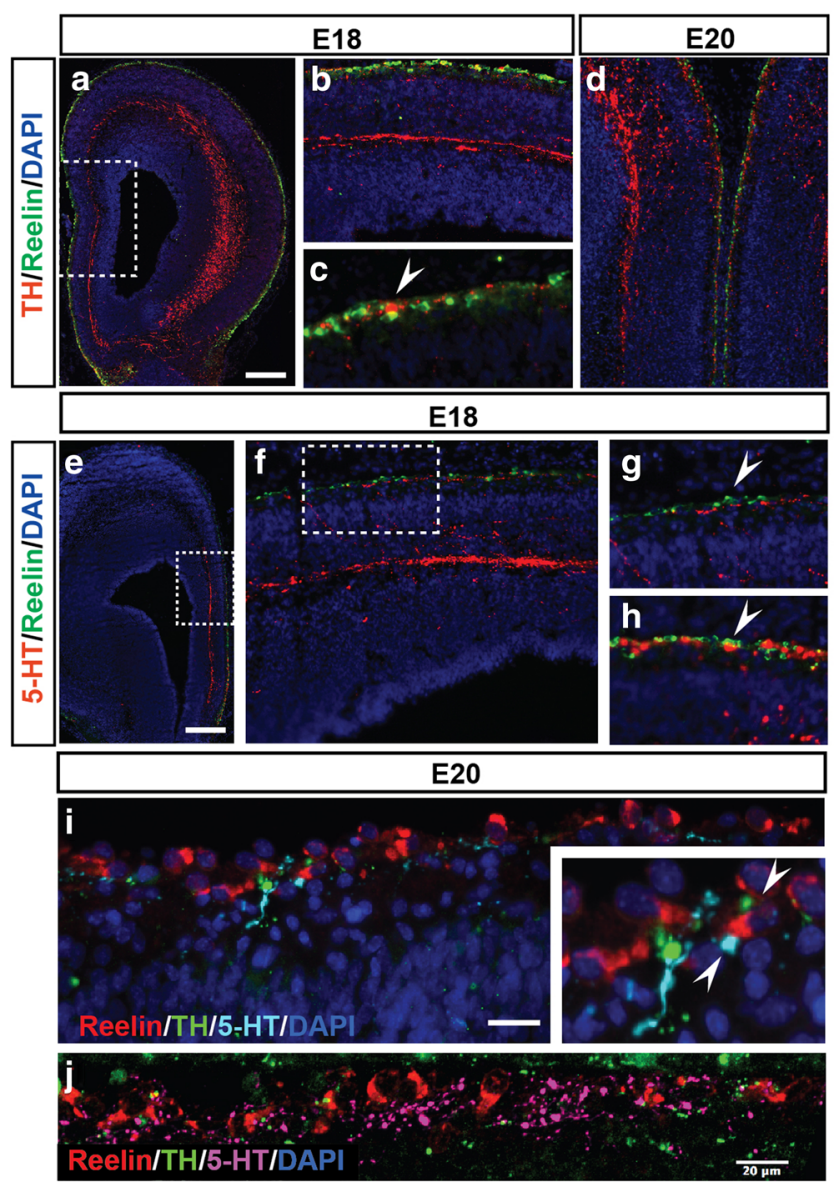

Fig. 5 The 5-HT and catecholaminergic systems are in close proximity of the CR cells. Coronal cryosections of E18 (a-c, e, and F) and E20 (d, i) rat brains immunostained for TH (red, a-d) or 5-HT (red, e-h) and reelin (green), counterstained with DAPI (blue). b, c Enlargements of the boxed area in a showing the $\mathrm{TH}$ fibers in close proximity to the reelin-positive $\mathrm{CR}$ cells. d Overview of the relation of $\mathrm{TH}$ innervation within the $\mathrm{mPFC}$ at E20. Coronal cryosections of an E18 rat brain immunostained for 5-HT (red, $\mathbf{e}-\mathbf{h}, \mathbf{i})$ and reelin (green), counterstained with DAPI (blue). $\mathbf{f}$ Enlargement of the boxed area in e showing the 5-HT fibers in close proximity to the reelin-positive Cajal-Retzius (CR) cells. g Enlargement of the boxed area in $\mathbf{f}$ showing the 5-HT fibers in close proximity to the reelin-positive CR cells. $\mathbf{h}$ Enlargement of the septal region in e showing the 5-HT fibers in close proximity to the reelin-positive CR cells. i E20 cryosection stained for TH (green), 5-HT (light blue) and reelin (red) and counterstained with DAPI (blue). Inset shows the close proximity of the TH and 5-HT fibers with the CR cells. $\mathbf{j}$ Confocal image of the marginal zone showing $\mathrm{TH}$ (green) and 5-HT fibers (purple) in close proximity to reelin-positive CR cells (red). Bar in a and e, $300 \mu \mathrm{m} ; \mathbf{i}, 30 \mu \mathrm{m} ; \mathbf{j}, 20 \mu \mathrm{m}$

for two different deep-layer markers; Tbr1 and Satb2 (Fig. 6ko). Expression levels of both markers were more restricted to the deeper layers in the wildtype brains and most affected when 5-HTT was absent (Fig. 6m-o). This suggests that, even though the percentage of cells expressing deep-layer markers catch up a bit at P25 reflecting some sort of developmental delay, a large portion will not be able to express these markers.

Reelin-positive interneurons will dispense throughout the cerebral wall in early postnatal ages [36,37,63]. Even though the ontogeny of reelin-positive CR cells and the reelin- positive GABAergic interneurons differ in their ontogeny [64], we pursued to find out whether the number and integration of reelin-positive cells was affected by the lack of 5-HTT during the course of development. We counted the reelinpositive cells in the P6 mutant and the control animals. We discovered that in all subdomains of the $\mathrm{mPFC}$, the number and distribution of reelin-positive neurons was affected in the 5-HTT ${ }^{-/-}$animals as compared to wildtypes (Fig. 7). In the IL, only bins 2, 5, and 6 showed lower number of reelin-positive cells (Fig. 7a, b), while in the PL, all bins except for 4, 5, and 8 showed significant lower numbers of reelin-positive cells (Fig. 7d, e). Within the Cg, bins 4, 6, 9, and 10 showed significant lower numbers of reelin-positive cells (Fig. 7g, h). Together, we found a decrease in the total number of reelinpositive cells in all subdomains although the number did not reach significance within the IL (Fig. 7c, f, and i). This suggests that the integration and/or number of reelin-positive interneurons within the subdomains of the mPFC is affected as well.

In all, we observed a strong interdependence between the developing 5-HT and catecholaminergic system. In the absence of 5-HTT, we found significant differences in the shape (rVTA) and in the shape and content (DR/MnR) of the origins of both neural systems, a striking increase of both 5-HT and catecholaminergic innervations of the $\mathrm{mPFC}$, altered deeplayer identity of mPFC neurons, and a decrease in reelinpositive cells, and which is summarized in Fig. 8.

\section{Discussion}

In this study, we show the coinciding development of the 5HT and the catecholaminergic systems between E16 and P25 within their origin, their outgrowing projections through the MFB and their common projection target, the $\mathrm{MPFC}$. In addition, our results demonstrate that in the absence of the 5-HTT and next to the 5-HT, also the catecholaminergic system and their projections towards the $\mathrm{mPFC}$ are altered. We further demonstrate that within the mPFC, the TH and 5-HT fibers are in close proximity to reelin-containing CR cells, and are different in number when 5-HTT is lacking. We also observe that, with differences in 5-HT/TH innervation of the mPFC, prefrontal cell identity is altered. Altogether, these data suggest that there is a functional interplay between the 5-HT and catecholaminergic systems during development with an effect on the proper cytoarchitecture of the PFC.

\section{Catecholaminergic and 5-HT Control of Prefrontal Development}

It is now well accepted that 5-HT plays an important role during neurodevelopment and that any disturbance of the system could add to the risk of developing neuropsychiatric 


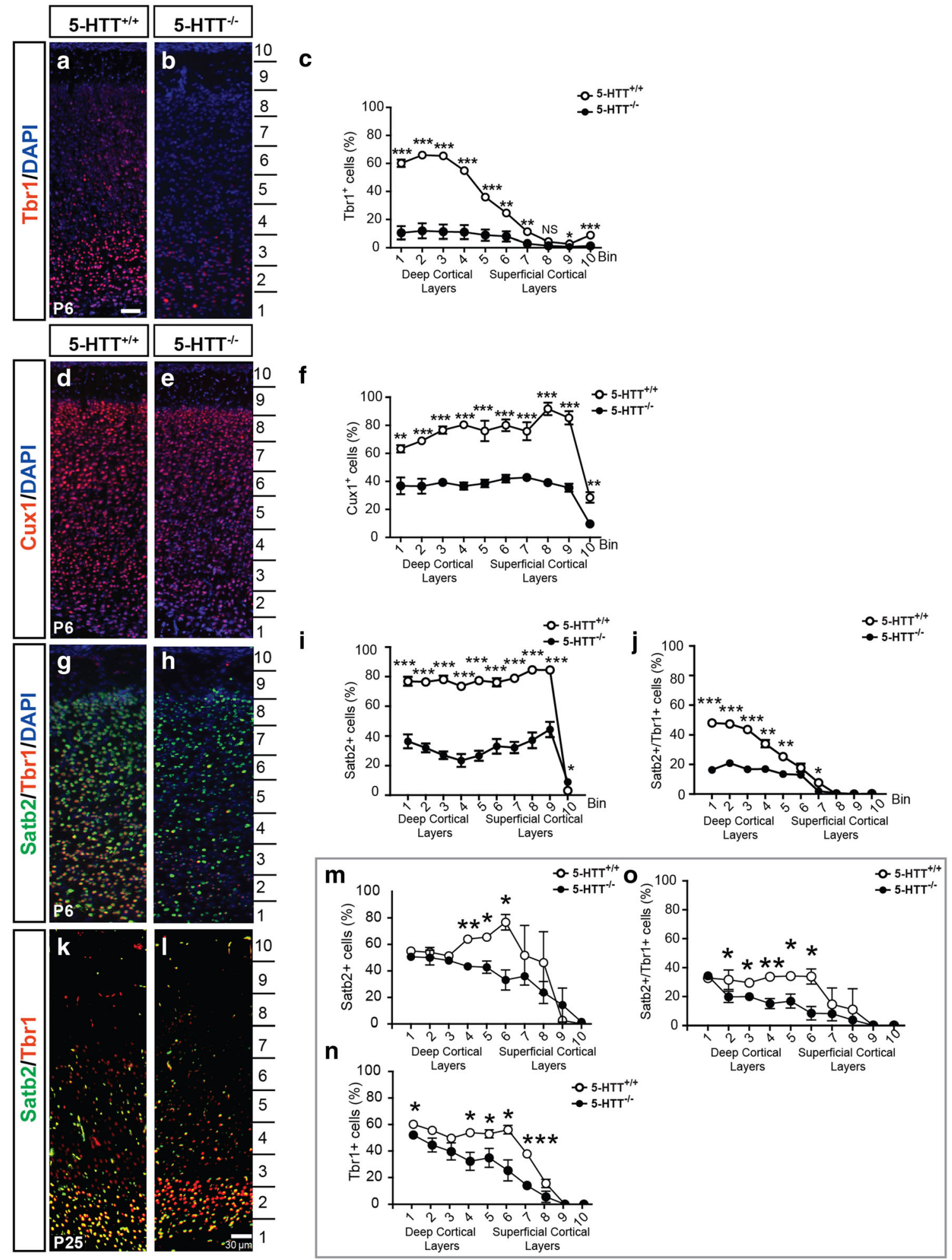

conditions [30, 65-67]. There is considerable genetic diversity among 5-HT neurons resulting in a vast and meticulously constructed network projecting to a large variety of targets $[8,24,68,69]$. The development of this heterogeneous pool of 5-HT neurons is under the control of intrinsic factors (e.g., transcription factors) and in interplay with extrinsic factors (e.g., guidance cues or cell adhesion molecules) that can steer the targeting projections [70-75]. Prefrontal 5-HT neurons arise in the rostral raphe cluster and the ascending axonal projections bundle up within the MFB and the fascicles traverse through the septal area towards the $\operatorname{mPFC}[6,23,76]$. Here, they are bundled in two paths; one within the superficial 
4 Fig. 6 Prefrontal cytoarchitecture is affected in the absence of 5-HTT. Enlargements of cryosections of P6 5-HTT ${ }^{+/+}$and $5-\mathrm{HTT}^{-/-}$rat brains showing prefrontal swatches of the PL immunostained for Tbrl (red, a, b) or Cux 1 (red, d, e) and counterstained with DAPI (blue). b, e Quantification of the percentage of Tbr1-positive (c) or Cux1-positive (f) neurons within the bins indicated in $\mathbf{a}, \mathbf{b}, \mathbf{d}$, and $\mathbf{e} . \mathbf{g}, \mathbf{h}$ Enlargements of cryosections of P6 5-HTT ${ }^{+/+}$and $5-\mathrm{HTT}^{-/-}$rat brains showing prefrontal swatches of the PL double-immunostained for Tbr1 (red) and Satb2 (green) and counterstained with DAPI (blue). i Quantification of the percentage of Satb2-positive neurons within the bins indicated in $\mathbf{h}$. $\mathbf{j}$ Quantification of the percentage of Satb2/Tbr1 double-positive neurons within the bins indicated in $\mathbf{h}$. $\mathbf{k}, \mathbf{l}$ Enlargements of cryosections of $\mathrm{P} 255-\mathrm{HTT}^{+/+}$and $5-\mathrm{HTT}^{-/-}$rat brains showing prefrontal swatches of the PL double-immunostained for Tbr1 (red) and Satb2 (green). m Quantification of the percentage of Satb2positive neurons within the bins indicated in $\mathbf{l}$. $\mathbf{n}$ Quantification of the percentage of Satb2-positive neurons within the bins indicated in l. o Quantification of the percentage of Satb2/Tbr1 double-positive neurons within the bins indicated in $\mathbf{l}$. Graphs in $\mathbf{c}-\mathbf{0}$ show average percentage \pm SEM. One-way ANOVA, ${ }^{* *} p<0.01,{ }^{* * *} p<0.001$. Bar in $\mathbf{a}-\mathbf{l}, 100 \mu \mathrm{m}$

Fig. 7 The number of reelinpositive cells is diminished in the absence of 5-HTT. Enlargements of cryosections of P6 5-HTT ${ }^{+/+}$ and $5-\mathrm{HTT}^{-/-}$rat brains showing prefrontal swatches of the IL (a), PL (d), and the $\mathrm{Cg}(\mathrm{g})$ immunostained for reelin (red) and counterstained with DAPI (blue). Quantification of the percentage of reelin-positive neurons within the bins indicated in $\mathbf{a}, \mathbf{d}$, and $\mathbf{g}$ in the IL (b), PL (e), and $\mathrm{Cg}(\mathbf{h})$ of $5-\mathrm{HTT}^{-/}$compared to $5-\mathrm{HTT}^{+/+}$pups confirming the qualitative observations. Graphs in $\mathbf{b}, \mathbf{e}$, and $\mathbf{h}$ show average percentage of reelin-positive neurons normalized to total number of cells per bin \pm SEM. One-way ANOVA, ${ }^{*} p<0.05,{ }^{* *} p$ $<0.01,{ }^{* * * *} p<0.001$.

Quantification of the total number of reelin-positive cells over the complete length of the prefrontal swatch in the IL (c), PL (f), and

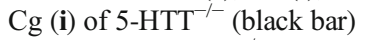
compared to $5-\mathrm{HTT}^{+/+}$pups (white bar). Graphs in $\mathbf{c}, \mathbf{f}$, and $\mathbf{i}$ show average number \pm SEM. One-way ANOVA, ${ }^{* *} p<0.01$, *** $p<0.001$. Bar in $\mathbf{a}-\mathbf{g}, 100 \mu \mathrm{m}$

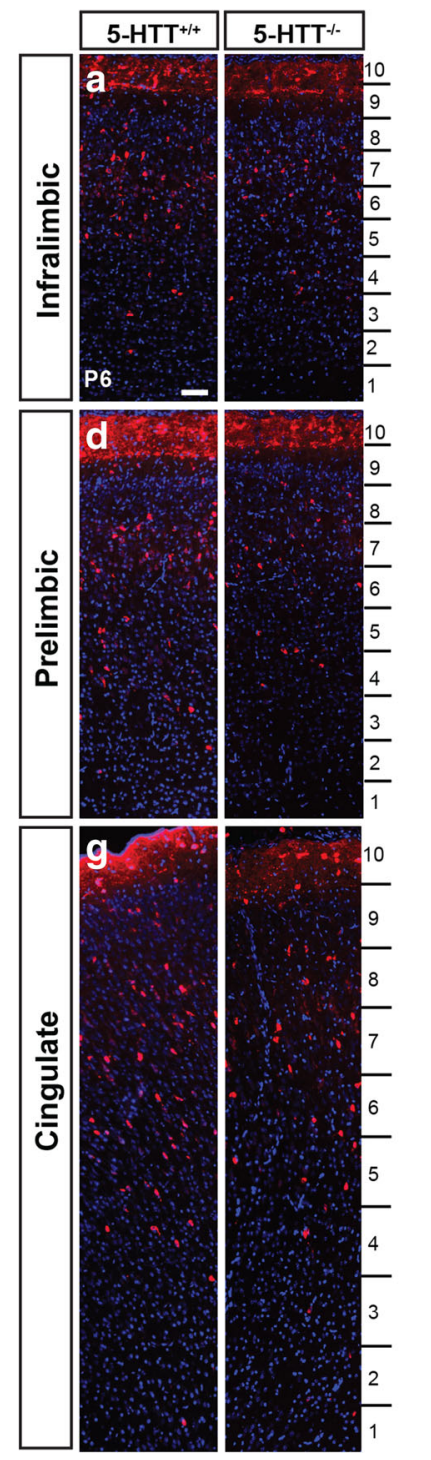

$\mathrm{MZ}$ and one on top of the SP underneath the CP which they innervate after a short waiting period [6, 23, 77]. Essentially, the same developmental trajectory holds true for the mesoprefrontal catecholaminergic projections, although the catecholaminergic system reaches the mPFC earlier [42, 43, 49]. Within the $M Z$ and presumptive layer I of the $\mathrm{mPFC}$, we observed 5-HT- and TH-positive varicosities in very close proximity of the reelin-positive CR cells. Synaptic structures, stained with either pre- or postsynaptic markers, could shed light on to what degree the CR cells receive TH- and/or 5-HTsynaptic inputs during development. In addition, varicosities do not necessarily have to imply synapses but can be a reflection of the complex that uses diffuse/volume transmission to communicate [78-80]. Nonetheless, there is certainly a spatial closeness of $5-\mathrm{HT}^{+}$as well as $\mathrm{TH}^{+}$fibers that could imply the ability to influence CR output and maybe even reelin release. Reelin is known for its ability to direct cortical layer formation b

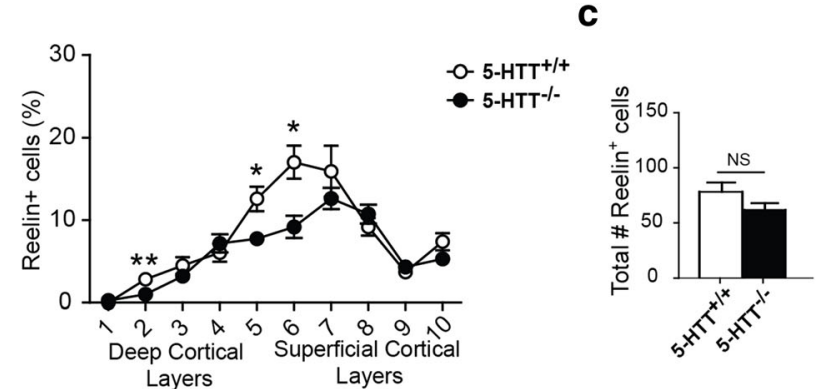

e

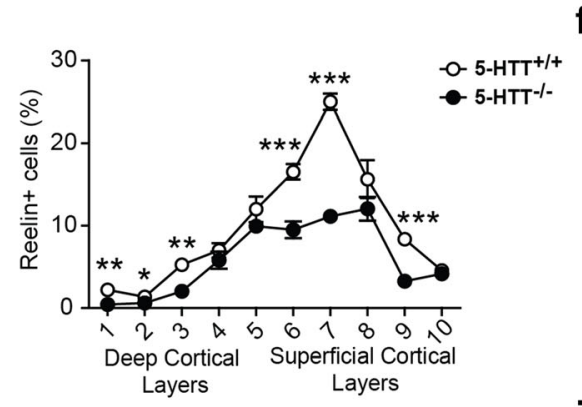

h

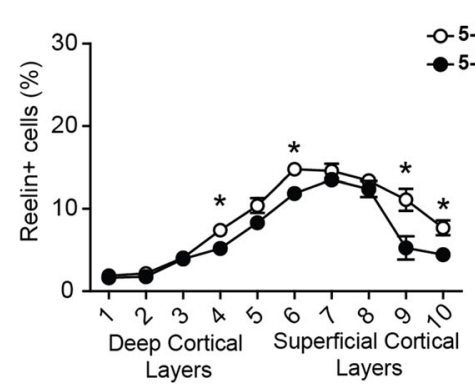

f

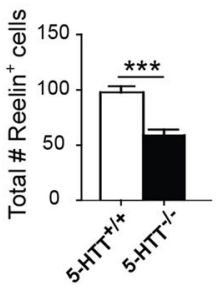

i

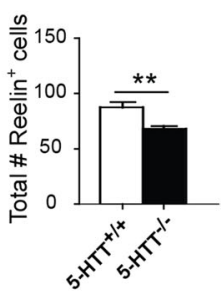




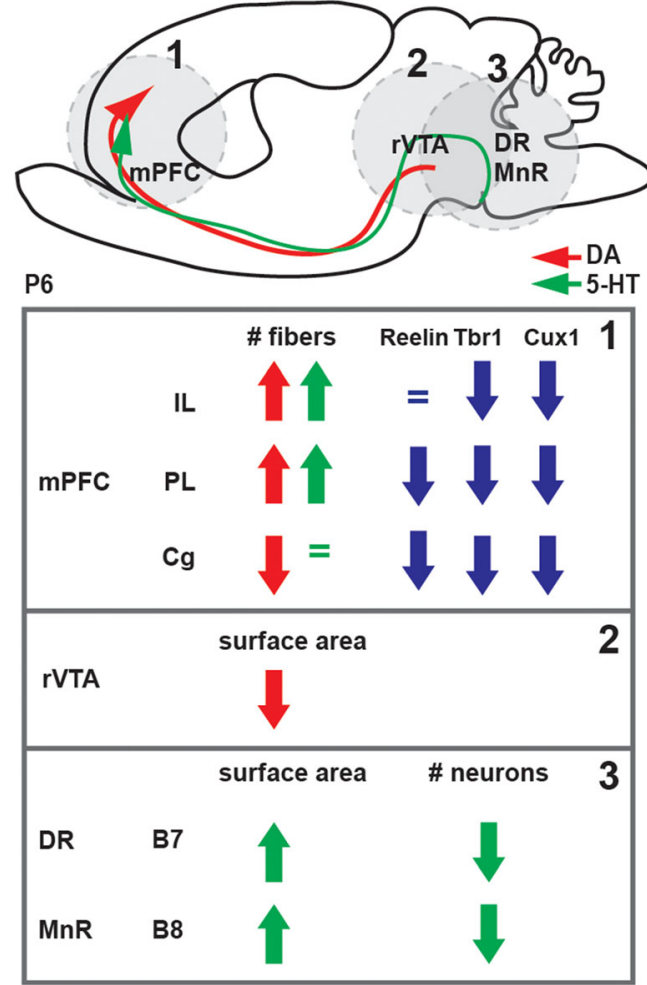

Fig. 8 Schematic overview of the results observed in the 5-HTT rat model. DA dopaminergic, Cg cingulate, DR dorsal raphe, 5-HT serotonergic, IL infralimbic, MnR medial raphe; $\mathrm{mPFC}$ medial prefrontal cortex, PL prelimbic, rVTA rostral ventral tegmental area

$[81,82]$. However, the developmental role of the effect of 5HT, DA, or other neurotransmitters on reelin release needs to be further characterized.

\section{Direct or Indirect Effects of 5-HTT on Cortical Integrity}

One critical way by which extracellular 5-HT levels can be controlled is through expression of 5-HTT. The transporter can clear 5-HT from the synaptic cleft to maintain homeostasis [83]. Remarkably, the expression of 5-HTT is already quite robust in early development, even before serotonergic axons have reached their targets $[60,84]$. What does this imply? It is known that there is an extra-embryonic source of 5-HT from the placenta that could regulate certain aspects of central nervous system development $[30,85,86]$. Yet, many questions remain. Narboux-Nème and colleagues [60] elegantly showed a transient 5-HTT expression within layers II, V, and VI of the $\mathrm{mPFC}$ at E15.5, thus even before 5-HT fibers reach the mPFC. Could it be that these deep-layer cortical neurons are most affected by the absence of 5-HTT and the resulting elevation of extracellular 5-HT? We indeed observed that in both layers $\mathrm{V}$ and VI as well as more superficial aspects of the prefrontal subareas, 5-HT- and TH-innervation were altered in the absence of 5-HTT. In addition, in our experiments, the number of predominantly deep-layer but also of the superficial-layer neurons was affected in the absence of 5-HTT at P6. At P25, however, we still see this effect for two different deep-layer markers (Tbr1 and Satb2); however, there is some percentage expression that does express these markers in the mutant suggesting a developmental delay. There are no indications that proliferation or migration (data not shown) was affected. Altamura and colleagues showed that in 5-HTT-deficient mice there are differences in cell density and layer thickness [87]. Does this mean that there is a different window of expression of layer-specific markers Cux1 and Tbr1 when 5-HTT is absent? At this point, it is hard to conclude whether this change in expression of layer markers is due to cell-autonomous effects (absence of 5-HTT) or cell non-autonomous effects (differences in innervation patterns/reelin effect), or a combination of both. Experiments using conditional mutants [88] that have a cell-type-specific deletion of 5-HTT could shed more light on this.

\section{Interaction of the Developing Catecholaminergic and 5-HT Systems}

Numerous studies have proven that there is an interdependence between 5-HT and DA [11, 15, 16, 18, 89], although less is known about this phenomenon during development. Both systems are able to influence neurodevelopmental events such as proliferation, migration, and differentiation $[30,51$, $62,90]$. But can one system be facilitated by the other during development? We showed that the $\mathrm{TH}^{+}$projections within subdomains of the mPFC are altered in absence of the 5HTT. Expression of 5-HTT has been found within virtually all DR neurons [60, 84, 91]. Are 5-HTT-deficient DR neurons able to alter the course of $\mathrm{TH}^{+}$projections? And if yes, what are the exact neurodevelopmental events of the developing DA neurons that can be influenced by the 5-HT system and at what developmental time points? Alongside the changes in 5-HT receptor expression [92-99], the expression of DA receptors and transporters might be altered as a consequence of a disrupted 5-HT system and DA system. This can result in changes in system sensitivity and excitability which would have extreme consequences for the maturation of cortical cells. For example, reelin-positive interneurons express the 5 -HT3A receptor $[64,100]$. Could changes in the 5-HT projection system have led to the changes we observed in the number and distribution of the reelin-positive cells? We need to have a complete picture of the spatial and temporal aspects of these developing systems in order to be able to design preventive measures or curative treatment without any side effects.

\section{Guidance of Interconnected Systems}

The 5-HT projections to target-selective forebrain regions are under the control of classical guidance molecules $[25,70,75]$. 
The 5-HT system is furthermore capable of modulating the responsiveness of axons to guidance cues such as netrins [62]. However, the catecholaminergic system reaches the mutual forebrain targets earlier than the 5-HT system does. Can it be that the altered catecholaminergic system development due to the absence of 5-HTT influences the developing mPFC earlier than the 5-HT and in a different manner? Or is it the absence of 5-HTT in target areas and within guidepost positions along the way that has changed guidance cue expression or the responsiveness of the $\mathrm{TH}^{+}$fibers? Even though the DR and $\mathrm{MnR}$ project to different targets, their development involves a common guidance family [101]. The differential expression of EphA5 and ephrina5, and consequential difference in Eph-ephrin signaling, steers the region-specific 5-HT innervation. Whether developing catecholaminergic projections within the same temporal and spatial window are also responsive to the same guidance cues as the 5-HT axons headed towards the $\mathrm{mPFC}$ remains to be established.

Neurodevelopmental processes may diverge in different brain regions and at various developmental time points. For example, the ontogeny of neurotransmitter systems can be affected by risk factors and aberrant projections may result $[1,9,10,22,50]$. Depending on the type of risk factor involved and their sensitive windows, which control the timing of when a disorder becomes overt, it is either the mPFC itself or its connected brain areas that may maldevelop. Yet, the net effect of faulty projections on other developing systems remains to be determined. Longitudinal studies at the systems level, including a complete inventory of the expression of a variety of neurotransmitter receptors and transporters in relation to the developing projections traveling together and their actions within the mPFC are needed. This would generate an important wealth of knowledge in order to understand the complexity of these interacting systems during development.

\section{Conclusions}

Our study shows a functional interplay between the 5-HT and catecholaminergic systems during development. As expected, due to the absence of the 5-HTT the 5-HT system was disturbed but we found that the catecholaminergic system was perturbed as well, together resulting in an altered maturation of the mPFC. Overall, the striking observation of both 5-HT and catecholaminergic hyperinnervation of prefrontal subregions highlights the need for precise system-oriented dissection of neural systems that concomitantly develop. The removal of only one building block may destabilize a plethora of interacting neurodevelopmental systems leading to impairment of cognitive functioning. This calls for more studies on the dissection of neurotransmitter systems-specific consequences on adult behavior to eventually allow the design of better treatment strategies for neuropsychiatric disorders.

Acknowledgements We thank the reviewers for critically reading this manuscript and members of the Martens, Kolk, and Homberg labs for their input. We thank the RIMLS microscopy platform (http://www.rimls. nl/technology-centers-old/microscope-imaging-centre/) for excellent support and maintenance of the equipment. We are grateful of Dr. C.L. S. Pontes for her excellent help with the confocal image acquisition.

Funding This work was supported by the Brazilian Coordenação de Aperfeiçoamento de Pessoal de Nível Superior or CAPES (BEX11914/ 13-0), and the Era-Net NEURON grant "RESPOND."

\section{Compliance with Ethical Standards}

Conflict of Interest The authors declare that they have no conflict of interest.

Open Access This article is distributed under the terms of the Creative Commons Attribution 4.0 International License (http:// creativecommons.org/licenses/by/4.0/), which permits unrestricted use, distribution, and reproduction in any medium, provided you give appropriate credit to the original author(s) and the source, provide a link to the Creative Commons license, and indicate if changes were made.

\section{References}

1. Schubert D, Martens GJ, Kolk SM (2015) Molecular underpinnings of prefrontal cortex development in rodents provide insights into the etiology of neurodevelopmental disorders. Mol Psychiatry 20(7):795-809. https://doi.org/10.1038/mp.2014.147

2. Curtis CE, Lee D (2010) Beyond working memory: the role of persistent activity in decision making. Trends Cogn Sci 14(5): 216-222. https://doi.org/10.1016/j.tics.2010.03.006

3. Arnsten AF (2015) Stress weakens prefrontal networks: molecular insults to higher cognition. Nat Neurosci 18(10):1376-1385. https://doi.org/10.1038/nn.4087

4. Selemon LD, Zecevic N (2015) Schizophrenia: a tale of two critical periods for prefrontal cortical development. Transl Psychiatry 5:e623. https://doi.org/10.1038/tp.2015.115

5. Kroeze Y, Oti M, van Beusekom E, Cooijmans RH, van Bokhoven H, Kolk SM, Homberg JR, Zhou H (2017) Transcriptome analysis identifies multifaceted regulatory mechanisms dictating a genetic switch from neuronal network establishment to maintenance during postnatal prefrontal cortex development. Cereb Cortex. https://doi.org/10.1093/cercor/bhw407

6. Janusonis S, Gluncic V, Rakic P (2004) Early serotonergic projections to Cajal-Retzius cells: relevance for cortical development. The Journal of neuroscience : the official journal of the Society for Neuroscience 24(7):1652-1659. https://doi.org/10.1523/ JNEUROSCI.4651-03.2004

7. Kabanova A, Pabst M, Lorkowski M, Braganza O, Boehlen A, Nikbakht N, Pothmann L, Vaswani AR et al (2015) Function and developmental origin of a mesocortical inhibitory circuit. Nat Neurosci 18(6):872-882. https://doi.org/10.1038/nn.4020

8. Roeper J (2013) Dissecting the diversity of midbrain dopamine neurons. Trends Neurosci 36(6):336-342. https://doi.org/10.1016/ j.tins.2013.03.003

9. Kolk SM, Gunput RA, Tran TS, van den Heuvel DM, Prasad AA, Hellemons AJ, Adolfs Y, Ginty DD et al (2009) Semaphorin 3F is 
a bifunctional guidance cue for dopaminergic axons and controls their fasciculation, channeling, rostral growth, and intracortical targeting. J Neurosci: Off J Soc Neurosci 29(40):12542-12557. https://doi.org/10.1523/JNEUROSCI.2521-09.2009

10. Witteveen JS, Middelman A, van Hulten JA, Martens GJ, Homberg JR, Kolk SM (2013) Lack of serotonin reuptake during brain development alters rostral raphe-prefrontal network formation. Front Cell Neurosci 7:143. https://doi.org/10.3389/fncel. 2013.00143

11. Hensler JG, Artigas F, Bortolozzi A, Daws LC, De Deurwaerdere P, Milan L, Navailles S, Koek W (2013) Catecholamine/serotonin interactions: systems thinking for brain function and disease. Adv Pharmacol 68:167-197. https://doi.org/10.1016/B978-0-12411512-5.00009-9

12. Bortolozzi A, Diaz-Mataix L, Scorza MC, Celada P, Artigas F (2005) The activation of 5-HT receptors in prefrontal cortex enhances dopaminergic activity. J Neurochem 95(6):1597-1607. https://doi.org/10.1111/j.1471-4159.2005.03485.x

13. Diaz-Mataix L, Scorza MC, Bortolozzi A, Toth M, Celada P, Artigas F (2005) Involvement of 5-HT1A receptors in prefrontal cortex in the modulation of dopaminergic activity: role in atypical antipsychotic action. The Journal of neuroscience : the official journal of the Society for Neuroscience 25(47):10831-10843. https://doi.org/10.1523/JNEUROSCI.2999-05.2005

14. Arnsten AF, Wang M (2016) Targeting prefrontal cortical systems for drug development: potential therapies for cognitive disorders. Annu Rev Pharmacol Toxicol 56:339-360. https://doi.org/10. 1146/annurev-pharmtox-010715-103617

15. Di Giovanni G, Di Matteo V, Esposito E (2008) Serotonindopamine interaction: experimental evidence and therapeutic relevance. Preface. Prog Brain Res 172:ix. https://doi.org/10.1016/ S0079-6123(08)00931-X

16. Esposito E, Di Matteo V, Di Giovanni G (2008) Serotonindopamine interaction: an overview. Prog Brain Res 172:3-6. https://doi.org/10.1016/S0079-6123(08)00901-1

17. Oades RD (2008) Dopamine-serotonin interactions in attentiondeficit hyperactivity disorder (ADHD). Prog Brain Res 172:543565. https://doi.org/10.1016/S0079-6123(08)00926-6

18. Di Matteo V, Pierucci M, Esposito E, Crescimanno G, Benigno A, Di Giovanni G (2008) Serotonin modulation of the basal ganglia circuitry: therapeutic implication for Parkinson's disease and other motor disorders. Prog Brain Res 172:423-463. https://doi.org/10. 1016/S0079-6123(08)00921-7

19. Ryding E, Lindstrom M, Traskman-Bendz L (2008) The role of dopamine and serotonin in suicidal behaviour and aggression. Prog Brain Res 172:307-315. https://doi.org/10.1016/S00796123(08)00915-1

20. Remington G (2008) Alterations of dopamine and serotonin transmission in schizophrenia. Prog Brain Res 172:117-140. https:// doi.org/10.1016/S0079-6123(08)00906-0

21. de Almeida J, Palacios JM, Mengod G (2008) Distribution of 5HT and DA receptors in primate prefrontal cortex: implications for pathophysiology and treatment. Prog Brain Res 172:101-115. https://doi.org/10.1016/S0079-6123(08)00905-9

22. Akil M, Pierri JN, Whitehead RE, Edgar CL, Mohila C, Sampson AR, Lewis DA (1999) Lamina-specific alterations in the dopamine innervation of the prefrontal cortex in schizophrenic subjects. Am J Psychiatry 156(10):1580-1589. https://doi.org/10.1176/ajp.156.10. 1580

23. Lidov HG, Molliver ME (1982) Immunohistochemical study of the development of serotonergic neurons in the rat CNS. Brain Res Bull 9(1-6):559-604

24. Kiyasova V, Gaspar P (2011) Development of raphe serotonin neurons from specification to guidance. Eur J Neurosci 34(10): 1553-1562. https://doi.org/10.1111/j.1460-9568.2011.07910.x
25. Muzerelle A, Scotto-Lomassese S, Bernard JF, Soiza-Reilly M, Gaspar P (2016) Conditional anterograde tracing reveals distinct targeting of individual serotonin cell groups (B5-B9) to the forebrain and brainstem. Brain Struct Funct 221(1):535-561. https:// doi.org/10.1007/s00429-014-0924-4

26. Fernandez SP, Cauli B, Cabezas C, Muzerelle A, Poncer JC, Gaspar P (2016) Multiscale single-cell analysis reveals unique phenotypes of raphe 5-HT neurons projecting to the forebrain. Brain Struct Funct 221(8):4007-4025. https://doi.org/10.1007/ s00429-015-1142-4

27. Bang SJ, Jensen P, Dymecki SM, Commons KG (2012) Projections and interconnections of genetically defined serotonin neurons in mice. Eur J Neurosci 35(1):85-96. https://doi.org/10. 1111/j.1460-9568.2011.07936.x

28. Homberg JR, Kolk SM, Schubert D (2013) Editorial perspective of the research topic "Deciphering serotonin's role in neurodevelopment". Front Cell Neurosci 7:212. https://doi.org/ $10.3389 /$ fncel.2013.00212

29. van Kleef ES, Gaspar P, Bonnin A (2012) Insights into the complex influence of 5-HT signaling on thalamocortical axonal system development. Eur J Neurosci 35(10):1563-1572. https://doi.org/ $10.1111 / j .1460-9568.2012 .8096 . x$

30. Gaspar P, Cases O, Maroteaux L (2003) The developmental role of serotonin: news from mouse molecular genetics. Nat Rev Neurosci 4(12):1002-1012. https://doi.org/10.1038/nrn1256

31. Trowbridge S, Narboux-Neme N, Gaspar P (2011) Genetic models of serotonin (5-HT) depletion: what do they tell us about the developmental role of 5-HT? Anat Rec 294(10):1615-1623. https://doi.org/10.1002/ar.21248

32. Azmitia EC (2001) Modern views on an ancient chemical: serotonin effects on cell proliferation, maturation, and apoptosis. Brain Res Bull 56(5):413-424

33. Radnikow G, Feldmeyer D, Lubke J (2002) Axonal projection, input and output synapses, and synaptic physiology of CajalRetzius cells in the developing rat neocortex. J Neurosci: Off $\mathrm{J}$ Soc Neurosci 22 (16):6908-6919. doi: 20026725

34. Naqui SZ, Harris BS, Thomaidou D, Parnavelas JG (1999) The noradrenergic system influences the fate of Cajal-Retzius cells in the developing cerebral cortex. Brain research. Dev Brain Res 113(1-2):75-82

35. Sekine K, Honda T, Kawauchi T, Kubo K, Nakajima K (2011) The outermost region of the developing cortical plate is crucial for both the switch of the radial migration mode and the Dab1-dependent "inside-out" lamination in the neocortex. The Journal of neuroscience: the official journal of the Society for Neuroscience 31(25): 9426-9439. https://doi.org/10.1523/JNEUROSCI.0650-11.2011

36. Jossin Y, Cooper JA (2011) Reelin, Rap1 and N-cadherin orient the migration of multipolar neurons in the developing neocortex. Nat Neurosci 14(6):697-703. https://doi.org/10.1038/nn.2816

37. Franco SJ, Martinez-Garay I, Gil-Sanz C, Harkins-Perry SR, Muller U (2011) Reelin regulates cadherin function via Dab1/ Rap1 to control neuronal migration and lamination in the neocortex. Neuron 69(3):482-497. https://doi.org/10.1016/j.neuron. 2011.01.003

38. Jiang X, Wang G, Lee AJ, Stornetta RL, Zhu JJ (2013) The organization of two new cortical interneuronal circuits. Nat Neurosci 16(2):210-218. https://doi.org/10.1038/nn.3305

39. Wozny C, Williams SR (2011) Specificity of synaptic connectivity between layer 1 inhibitory interneurons and layer $2 / 3$ pyramidal neurons in the rat neocortex. Cereb Cortex 21(8):1818-1826. https://doi.org/10.1093/cercor/bhq257

40. Chowdhury TG, Jimenez JC, Bomar JM, Cruz-Martin A, Cantle JP, Portera-Cailliau C (2010) Fate of Cajal-Retzius neurons in the postnatal mouse neocortex. Front Neuroanat 4:10. https://doi.org/ 10.3389/neuro.05.010.2010 
41. Kalsbeek A, De Bruin JP, Feenstra MG, Uylings HB (1990) Agedependent effects of lesioning the mesocortical dopamine system upon prefrontal cortex morphometry and PFC-related behaviors. Prog Brain Res 85:257-282; discussion 282-253

42. Lammel S, Hetzel A, Hackel O, Jones I, Liss B, Roeper J (2008) Unique properties of mesoprefrontal neurons within a dual mesocorticolimbic dopamine system. Neuron 57(5):760-773. https://doi.org/10.1016/j.neuron.2008.01.022

43. Kalsbeek A, Voorn P, Buijs RM, Pool CW, Uylings HB (1988) Development of the dopaminergic innervation in the prefrontal cortex of the rat. J Comp Neurol 269(1):58-72. https://doi.org/ 10.1002/cne.902690105

44. Bodea GO, Blaess S (2015) Establishing diversity in the dopaminergic system. FEBS Lett 589(24 Pt A):3773-3785. https://doi. org/10.1016/j.febslet.2015.09.016

45. Zhang L, Bai J, Undie AS, Bergson C, Lidow MS (2005) D1 dopamine receptor regulation of the levels of the cell-cyclecontrolling proteins, cyclin D, P27 and Raf-1, in cerebral cortical precursor cells is mediated through cAMP-independent pathways. Cereb Cortex 15(1):74-84. https://doi.org/10.1093/cercor/bhh110

46. Spencer GE, Klumperman J, Syed NI (1998) Neurotransmitters and neurodevelopment. Role of dopamine in neurite outgrowth, target selection and specific synapse formation. Perspect Dev Neurobiol 5(4):451-467

47. Stanwood GD, Parlaman JP, Levitt P (2005) Anatomical abnormalities in dopaminoceptive regions of the cerebral cortex of dopamine D1 receptor mutant mice. J Comp Neurol 487(3):270282. https://doi.org/10.1002/cne.20548

48. Lu H, Lim B, Poo MM (2009) Cocaine exposure in utero alters synaptic plasticity in the medial prefrontal cortex of postnatal rats. The Journal of neuroscience: the official journal of the Society for Neuroscience 29(40):12664-12674. https://doi.org/10.1523/ JNEUROSCI.1984-09.2009

49. Bhide PG (2009) Dopamine, cocaine and the development of cerebral cortical cytoarchitecture: a review of current concepts. Semin Cell Dev Biol 20(4):395-402. https://doi.org/10.1016/j. semcdb.2009.01.006

50. Money KM, Stanwood GD (2013) Developmental origins of brain disorders: roles for dopamine. Front Cell Neurosci 7:260. https:// doi.org/10.3389/fncel.2013.00260

51. Niederkofler V, Asher TE, Dymecki SM (2015) Functional interplay between dopaminergic and serotonergic neuronal systems during development and adulthood. ACS Chem Neurosci 6(7): 1055-1070. https://doi.org/10.1021/acschemneuro.5b00021

52. Pollak Dorocic I, Furth D, Xuan Y, Johansson Y, Pozzi L, Silberberg G, Carlen M, Meletis K (2014) A whole-brain atlas of inputs to serotonergic neurons of the dorsal and median raphe nuclei. Neuron 83(3):663-678. https://doi.org/10.1016/j.neuron. 2014.07.002

53. Herve D, Pickel VM, Joh TH, Beaudet A (1987) Serotonin axon terminals in the ventral tegmental area of the rat: fine structure and synaptic input to dopaminergic neurons. Brain Res 435(1-2):7183

54. Peyron C, Luppi PH, Kitahama K, Fort P, Hermann DM, Jouvet M (1995) Origin of the dopaminergic innervation of the rat dorsal raphe nucleus. Neuroreport 6(18):2527-2531

55. Yamazoe I, Takeuchi Y, Matsushita H, Kawano H, Sawada T (2001) Serotonergic heterotypic sprouting in the unilaterally dopamine-depleted mouse neostriatum. Dev Neurosci 23 (1):7883. doi: 48698

56. Smits BM, Mudde JB, van de Belt J, Verheul M, Olivier J, Homberg J, Guryev V, Cools AR et al (2006) Generation of gene knockouts and mutant models in the laboratory rat by ENU-driven target-selected mutagenesis. Pharmacogenet Genomics 16(3): 159-169. https://doi.org/10.1097/01.fpc.0000184960.82903.8f
57. Kolk SM, Whitman MC, Yun ME, Shete P, Donoghue MJ (2006) A unique subpopulation of Tbr1-expressing deep layer neurons in the developing cerebral cortex. Mol Cell Neurosci 32(1-2):200 214

58. Schambra UB, Lauder JM, Silver J(1992) Atlas of the prenatal mouse brain. Academic Press, San Diego. https://doi.org/10. 1016/C2009-0-02642-7

59. Jacobowitz DM, Abott LC(1998) Chemoarchitectonic atlas of the developing mouse brain. CRC Press, Boca Raton. https://scholar. google.com/scholar_lookup? author=DM+Jacobowitz\&author= LC+Abott\&title $=$ Chemoarchitectonic + atlas + of + the+developing+ mouse+brain\&publication_year=1998

60. Narboux-Neme N, Pavone LM, Avallone L, Zhuang X, Gaspar P (2008) Serotonin transporter transgenic (SERTcre) mouse line reveals developmental targets of serotonin specific reuptake inhibitors (SSRIs). Neuropharmacology 55(6):994-1005. https://doi. org/10.1016/j.neuropharm.2008.08.020

61. Buznikov GA, Lambert HW, Lauder JM (2001) Serotonin and serotonin-like substances as regulators of early embryogenesis and morphogenesis. Cell Tissue Res 305(2):177-186

62. Bonnin A, Torii M, Wang L, Rakic P, Levitt P (2007) Serotonin modulates the response of embryonic thalamocortical axons to netrin-1. Nat Neurosci 10(5):588-597. https://doi.org/10.1038/ nn1896

63. Kirischuk S, Luhmann HJ, Kilb W (2014) Cajal-Retzius cells: update on structural and functional properties of these mystic neurons that bridged the 20th century. Neuroscience 275:33-46. https://doi.org/10.1016/j.neuroscience.2014.06.009

64. Ledonne F, Orduz D, Mercier J, Vigier L, Grove EA, Tissir F, Angulo MC, Pierani A et al (2016) Targeted inactivation of bax reveals a subtype-specific mechanism of Cajal-Retzius neuron death in the postnatal cerebral cortex. Cell Rep 17(12):31333141. https://doi.org/10.1016/j.celrep.2016.11.074

65. Scott MM, Deneris ES (2005) Making and breaking serotonin neurons and autism. International journal of developmental neuroscience: the official journal of the International Society for Developmental Neuroscience 23(2-3):277-285. https://doi.org/ 10.1016/j.ijdevneu.2004.05.012

66. Gross C, Hen R (2004) The developmental origins of anxiety. Nat Rev Neurosci 5(7):545-552. https://doi.org/10.1038/nrn1429

67. Lucki I (1998) The spectrum of behaviors influenced by serotonin. Biol Psychiatry 44(3):151-162

68. Calizo LH, Akanwa A, Ma X, Pan YZ, Lemos JC, Craige C, Heemstra LA, Beck SG (2011) Raphe serotonin neurons are not homogenous: electrophysiological, morphological and neurochemical evidence. Neuropharmacology 61(3):524-543. https:// doi.org/10.1016/j.neuropharm.2011.04.008

69. Jensen P, Farago AF, Awatramani RB, Scott MM, Deneris ES, Dymecki SM (2008) Redefining the serotonergic system by genetic lineage. Nat Neurosci 11(4):417-419. https://doi.org/10. 1038/nn2050

70. Bagri A, Marin O, Plump AS, Mak J, Pleasure SJ, Rubenstein JL, Tessier-Lavigne M (2002) Slit proteins prevent midline crossing and determine the dorsoventral position of major axonal pathways in the mammalian forebrain. Neuron 33(2):233-248

71. Cheng L, Chen CL, Luo P, Tan M, Qiu M, Johnson R, Ma Q (2003) Lmx1b, Pet-1, and Nkx2.2 coordinately specify serotonergic neurotransmitter phenotype. J Neurosci: Off J Soc Neurosci 23(31):9961-9967

72. Cordes SP (2005) Molecular genetics of the early development of hindbrain serotonergic neurons. Clin Genet 68(6):487-494. https://doi.org/10.1111/j.1399-0004.2005.00534.x

73. Ding YQ, Marklund U, Yuan W, Yin J, Wegman L, Ericson J, Deneris E, Johnson RL et al (2003) Lmxlb is essential for the development of serotonergic neurons. Nat Neurosci 6(9):933938. https://doi.org/10.1038/nn1104 
74. Donovan SL, Mamounas LA, Andrews AM, Blue ME, McCasland JS (2002) GAP-43 is critical for normal development of the serotonergic innervation in forebrain. J Neurosci: Off J Soc Neurosci 22 (9):3543-3552. doi:20026295

75. Fenstermaker AG, Prasad AA, Bechara A, Adolfs Y, Tissir F, Goffinet A, Zou Y, Pasterkamp RJ (2010) Wnt/planar cell polarity signaling controls the anterior-posterior organization of monoaminergic axons in the brainstem. J Neurosci: Off J Soc Neurosci 30(47):16053-16064. https://doi.org/10.1523/JNEUROSCI. 4508-10.2010

76. Wallace JA, Lauder JM (1983) Development of the serotonergic system in the rat embryo: an immunocytochemical study. Brain Res Bull 10(4):459-479

77. D'Amato RJ, Blue ME, Largent BL, Lynch DR, Ledbetter DJ, Molliver ME, Snyder SH (1987) Ontogeny of the serotonergic projection to rat neocortex: transient expression of a dense innervation to primary sensory areas. Proc Natl Acad Sci U S A 84(12): 4322-4326

78. Paspalas CD, Goldman-Rakic PS (2004) Microdomains for dopamine volume neurotransmission in primate prefrontal cortex. J Neurosci: Off J Soc Neurosci 24(23):5292-5300. https://doi.org/ 10.1523/JNEUROSCI.0195-04.2004

79. Lapish CC, Kroener S, Durstewitz D, Lavin A, Seamans JK (2007) The ability of the mesocortical dopamine system to operate in distinct temporal modes. Psychopharmacology 191(3):609625. https://doi.org/10.1007/s00213-006-0527-8

80. Jennings KA (2013) A comparison of the subsecond dynamics of neurotransmission of dopamine and serotonin. ACS Chem Neurosci 4(5):704-714. https://doi.org/10.1021/cn4000605

81. Frotscher M (2010) Role for reelin in stabilizing cortical architecture. Trends Neurosci 33(9):407-414. https://doi.org/10.1016/j. tins.2010.06.001

82. Kon E, Cossard A, Jossin Y (2017) Neuronal polarity in the embryonic mammalian cerebral cortex. Front Cell Neurosci 11:163. https://doi.org/10.3389/fncel.2017.00163

83. Blakely RD, Berson HE, Fremeau RT Jr, Caron MG, Peek MM, Prince HK, Bradley CC (1991) Cloning and expression of a functional serotonin transporter from rat brain. Nature 354(6348):6670. https://doi.org/10.1038/354066a0

84. Zhou FC, Sari Y, Zhang JK (2000) Expression of serotonin transporter protein in developing rat brain. Brain research. Dev Brain Res 119(1):33-45

85. Bonnin A, Goeden N, Chen K, Wilson ML, King J, Shih JC, Blakely RD, Deneris ES et al (2011) A transient placental source of serotonin for the fetal forebrain. Nature 472(7343):347-350. https://doi.org/10.1038/nature09972

86. Vitalis T, Parnavelas JG (2003) The role of serotonin in early cortical development. Dev Neurosci 25 (2-4):245-256. doi:72272

87. Altamura C, Dell'Acqua ML, Moessner R, Murphy DL, Lesch KP, Persico AM (2007) Altered neocortical cell density and layer thickness in serotonin transporter knockout mice: a quantitation study. Cereb Cortex 17(6):1394-1401. https://doi.org/10.1093/ cercor/bh1051

88. Chen X, Ye R, Gargus JJ, Blakely RD, Dobrenis K, Sze JY (2015) Disruption of transient serotonin accumulation by non-serotoninproducing neurons impairs cortical map development. Cell Rep 10:346-358. https://doi.org/10.1016/j.celrep.2014.12.033

89. Monti JM, Jantos H (2008) The roles of dopamine and serotonin, and of their receptors, in regulating sleep and waking. Prog Brain Res 172:625-646. https://doi.org/10.1016/S0079-6123(08)009291
90. Crandall JE, McCarthy DM, Araki KY, Sims JR, Ren JQ, Bhide PG (2007) Dopamine receptor activation modulates GABA neuron migration from the basal forebrain to the cerebral cortex. $\mathrm{J}$ Neurosci: Off J Soc Neurosci 27(14):3813-3822. https://doi.org/ 10.1523/JNEUROSCI.5124-06.2007

91. Bruning G, Liangos O, Baumgarten HG (1997) Prenatal development of the serotonin transporter in mouse brain. Cell Tissue Res 289(2):211-221

92. Araragi N, Mlinar B, Baccini G, Gutknecht L, Lesch KP, Corradetti R (2013) Conservation of 5-HT1A receptor-mediated autoinhibition of serotonin (5-HT) neurons in mice with altered 5HT homeostasis. Front Pharmacol 4:97. https://doi.org/10.3389/ fphar.2013.00097

93. Homberg JR, De Boer SF, Raaso HS, Olivier JD, Verheul M, Ronken E, Cools AR, Ellenbroek BA et al (2008) Adaptations in pre- and postsynaptic 5-HT1A receptor function and cocaine supersensitivity in serotonin transporter knockout rats. Psychopharmacology 200(3):367-380. https://doi.org/10.1007/ s00213-008-1212-x

94. Fabre V, Beaufour C, Evrard A, Rioux A, Hanoun N, Lesch KP, Murphy DL, Lanfumey L et al (2000) Altered expression and functions of serotonin 5-HT1A and 5-HT1B receptors in knockout mice lacking the 5-HT transporter. Eur J Neurosci 12(7):2299 2310

95. Li Q, Wichems C, Heils A, Lesch KP, Murphy DL (2000) Reduction in the density and expression, but not G-protein coupling, of serotonin receptors (5-HT1A) in 5-HT transporter knockout mice: gender and brain region differences. The Journal of neuroscience: the official journal of the Society for Neuroscience 20(21):7888-7895

96. Qu Y, Villacreses N, Murphy DL, Rapoport SI (2005) 5-HT2A/2C receptor signaling via phospholipase $\mathrm{A} 2$ and arachidonic acid is attenuated in mice lacking the serotonin reuptake transporter. Psychopharmacology 180(1):12-20. https://doi.org/10.1007/ s00213-005-2231-5

97. Fox MA, Stein AR, French HT, Murphy DL (2010) Functional interactions between 5-HT2A and presynaptic 5-HT1A receptorbased responses in mice genetically deficient in the serotonin 5HT transporter (SERT). Br J Pharmacol 159(4):879-887. https:// doi.org/10.1111/j.1476-5381.2009.00578.x

98. Mossner R, Schmitt A, Hennig T, Benninghoff J, Gerlach M, Riederer P, Deckert J, Lesch KP (2004) Quantitation of 5HT3 receptors in forebrain of serotonin transporter deficient mice. J Neural Transm 111(1):27-35. https://doi.org/10.1007/s00702003-0074-y

99. Jennings KA, Licht CL, Bruce A, Lesch KP, Knudsen GM, Sharp $\mathrm{T}$ (2012) Genetic variation in 5-hydroxytryptamine transporter expression causes adaptive changes in 5-HT(4) receptor levels. Int J Neuropsychopharmacol 15(8):1099-1107. https://doi.org/ $10.1017 /$ S1461145711001258

100. Lee S, Hjerling-Leffler J, Zagha E, Fishell G, Rudy B (2010) The largest group of superficial neocortical GABAergic interneurons expresses ionotropic serotonin receptors. J Neurosci: Off J Soc Neurosci 30(50):16796-16808. https://doi.org/10.1523/ JNEUROSCI.1869-10.2010

101. Teng T, Gaillard A, Muzerelle A, Gaspar P (2017) EphrinA5 signaling is required for the distinctive targeting of raphe serotonin neurons in the forebrain. eNeuro 4 (1). https://doi.org/10.1523/ ENEURO.0327-16.2017 